\title{
Estimation of the Chlorophyll Concentration in Sorghum Using Three High Throughput Phenotyping Imaging Techniques
}

Huichun Zhang ( $\nabla$ njzhanghc@126.com )

Nanjing Forestry University https://orcid.org/0000-0002-6479-0641

Yufeng Ge

University of Nebraska-Lincoln

Xinyan Xie

University of Nebraska-Lincoln

Abbas Atefi

University of Nebraska-Lincoln

Nuwan Wijewardane

Mississippi State University

Suresh Thapa

University of Nebraska-Lincoln

\section{Research}

Keywords: Plant phenotyping, Chlorophyll concentration, Specific leaf weight, Partial least squares regression, High throughput, Image analysis

Posted Date: April 19th, 2021

DOI: https://doi.org/10.21203/rs.3.rs-407791/v1

License: (c) (i) This work is licensed under a Creative Commons Attribution 4.0 International License.

Read Full License 
Estimation of the chlorophyll concentration in sorghum using three high throughput phenotyping imaging techniques

Huichun Zhang ${ }^{1,2^{*}}$, Yufeng $\mathrm{Ge}^{2}$, Xinyan $\mathrm{Xie}^{3}$, Abbas Atefi ${ }^{2}$, Nuwan K. Wijewardane ${ }^{3}$, Suresh Thapa $^{4}$

1 College of Mechanical and Electronic Engineering, Nanjing Forestry University, Nanjing 210037, China

2 Department of Biological Systems Engineering, University of Nebraska-Lincoln, NE 68583, USA

3 Department of Agricultural \& Biological Engineering, Mississippi State University, Starkville, MS, USA

4 Department of Computer Science and Engineering, University of Nebraska-Lincoln, NE 68583, USA

- Correspondence: njzhanghc@hotmail.com;

\section{Abstract}

Background: Leaf chlorophyll content plays an important role in indicating plant stresses and nutrient status. Traditional approaches for the quantification of chlorophyll content mainly include acetone ethanol extraction, spectrophotometry and high-performance liquid chromatography. Such destructive methods based on laboratory procedures are time consuming, expensive, and not suitable for highthroughput phenotyping. High throughput imaging techniques are now widely used for nondestructive analysis of plant phenotypic traits. In this study three imaging modules, namely, RGB, hyperspectral, and fluorescence imaging, were used to estimate chlorophyll content of sorghum plants in a greenhouse environment. Color features, spectral indices, and chlorophyll fluorescence intensity were extracted from these three types of images, and regression models were built to predict leaf chlorophyll content (measured by a handheld leaf chlorophyll meter) from the image features.

Results: Models that included two additional variables, DAS (day after sowing) and SLW (specific leaf weight), were also investigated to improve the prediction of chlorophyll. $\mathrm{R}^{2}$ for chlorophyll concentration for multiple linear models at various color components were 0.77 for $\mathrm{R}, 0.79$ for $\mathrm{G}, 0.70$ 
for B. To obtain additional spectral information, color component $\mathrm{H}$, S, and I were calculated after color spaces being transformed. The result of HSI space showed that $\mathrm{R}^{2}$ for chlorophyll concentration for multiple linear models were 0.67 for $\mathrm{H}, 0.88$ for $\mathrm{S}, 0.77$ for $\mathrm{I}$. The $\mathrm{R}^{2}$ values for different hyperspectral index like the ratio vegetation index (RVI), the normalized difference vegetation index (NDVI), modified chlorophyll absorption ratio index (MCARI) between 0.77 and $0.78 . \mathrm{R}^{2}=0.79$ was obtained with fluorescence image. Partial least squares regression (PLSR) was employed to using the selected vegetation indices computed from different imaging data to estimate the chlorophyll concentration for sorghum plants. Among all the imaging data, chlorophyll content was predicted with high accuracy ( $\mathrm{R}^{2}$ from 0.84 to 2.92 , RPD from 2.49 to 3.58 ).

Conclusion: According to the Akaike's Information Criterion (AIC) error function, the model was better fitted based on images, DAS and SLW than that based on images and DAS. This study indicated that the accuracy for chlorophyll estimation was increased by the image traits combined with DAS and SLW. High throughput imaging provides a simple, rapid, and nondestructive method to estimate the leaf chlorophyll concentration.

Key words: Plant phenotyping, Chlorophyll concentration, Specific leaf weight, Partial least squares regression, High throughput, Image analysis.

\section{Background}

Chlorophyll constituents a major component of plant leaves and it is a useful indicator of the overall health condition of the plant. Chlorophyll is the most important pigment for photosynthesis and growth. The determination of chlorophyll content in plant leaves can be used to investigate plant physiological and nutritional status, and consequently has important implications on crop stress and pests detection 
(such as in precision agriculture practices (Jin et al., 2020)). Generally, as plant stress levels increase, chlorophyll levels tend to decrease (Schuerger et al., 2003). Traditional approaches for the quantification of chlorophyll content mainly include acetone ethanol extraction, spectrophotometry and high-performance liquid chromatography. Such destructive methods based on laboratory procedures are time consuming, expensive, and not suitable for high-throughput phenotyping. Using spectroscopy and a portable chlorophyll meter, several spectral indices have been identified, which can be used for predicting chlorophyll concentration in plant tissues in vivo non-destructively (Jespersen et al., 2016). However, manually operated portable chlorophyll meters are relatively subjective, and spectroscopy techniques can't be used to digitize the chlorophyll distribution in plant leaves. It is clear that these two methods are too labor-intensive to meet the needs of large-scale screening programs.

Development of phenotyping tools and methods for both proximal and remote sensing accelerates handling massive amounts of plant imaging data. For chlorophyll estimation trials, satellite imaging is useful for evaluation of moderate to large sized trial plots while for smaller plots, remote sensing with unmanned aerial vehicles (UAVs) and proximal phenotyping are viable alternatives. Satellite imaging could be especially valuable for trials which are often replicated at different locations to study genotype by environment interactions (Chawade et al., 2019). As trials are often performed with different stress, proximal phenotyping could be a viable tool for evaluating chlorophyll estimation in greenhouse. For proximal phenotyping, sensors can be handheld or mounted on phenotyping platforms (Andrianto et al., 2017).

Rapid and non-invasive approaches for the screening and quantification of plant traits are 
particularly anticipated in plant breeding programs. With the establishment of advanced technology facilities for high throughput plant phenotyping (Fahlgren et al., 2015), estimating chlorophyll content of individual plants from their images becomes possible. This imaging based approach is more desirable than handheld chlorophyll meters, because it eliminates the involvement of human labor and further improves measurement throughput. Meanwhile, plants can be imaged by several of these imaging modalities, allowing accurate in vivo evaluation of many aspects of plant traits simultaneously. Conceivably, measurements of a large number of plants (e.g., hundreds) is possible, and measurements can be done at multiple time points across the entire life cycle of the plants which enables temporal dynamic analysis (Yang et al., 2020).

With the advancement in sensor technologies, high-throughput plant phenotyping (HTPP) has become more widely available for the research community, in particular the high-throughput imaging technology. Many believe that image acquisition is no longer the challenge; the true bottleneck is in the analysis of thousands of plant images that can be acquired in a short time window (Roitsch, 2019). Image-based features extracted from images, which contain the information on the morphological and biochemical traits of plants, enable effective use of genomic data to bridge the genotype-to-phenotype gap for crop improvement.

The imaging processing techniques have recently been used for remote detecting Chl content. After obtaining the image, the chlorophyll content could be predicted by image segmentation and feature extraction, and it is an essential basis for precision management. Image analysis method has been used to an alternate choice for quantificational predicting the chlorophyll distribution in some plants. Three leaves were cut from the main stem of each rice plant and scanned using a hyperspectral 
camera. Models were built to quantify chlorophyll content and determined the important bands associated with Chl. The $\mathrm{R}^{2}$ values of the models were 0.827-0.928 (Feng et al., 2017). The leaves of micropropagated potato plants were scanned by the HP scan jet 3670 scanner to acquire image. A good correlations between the predicted and actual chlorophyll content was observed with RGB model and the $\mathrm{R}^{2}$ values were $0.42-0.77$ (Yadav et al., 2010). The leaves of four commercial cultivars were removed from the plants were placed flat on the light box and photographed by a digital color camera. The results showed that $(\mathrm{R}-\mathrm{B}) /(\mathrm{R}+\mathrm{B})$ is the most fitted function of RGB space to estimate the $\mathrm{Chl}$ content of leaves (Mahmoodi et al., 2013). Four leaf disks were cut form tabacoo and grapevine leaves and photographed with a digital camera. The results suggested the relationship between photographic estimated and actual values of chlorophyll content was fitted well $\left(\mathrm{R}^{2}=0.883\right)$ (Majer et al., 2010).

The previous research provided the parameter extraction method from one individual leaf image, the leaves which were surgically removed from the plant were placed flat and scanned by camera, and then chlorophyll detection model was constructed to analyze leaves' chlorophyll content. However, it is not possible to follow developmental stages plant using such destructive methods. Additionally, the image analysis of an individual plant in vivo on a large scale has not been previously applied to the chlorophyll content estimation. It is possible to make spatially resolved predictions for the $\mathrm{Chl}$ concentration at the whole plant level. It would be a tool to quantify the spatial distribution of Chl content within the plant at multiple time points along the life cycle. If it can accurately work on predicting the chlorophyll content, the approach of image analysis could provide a rapid monitoring and screening technique to identify genotypes of high chlorophyll in large breeding populations for covering more growth stages. 
In this paper, we present our work for non-destructive estimation of leaf chlorophyll content in sorghum using image-based traits derived from several imaging modules. We used a mini diversity panel of 15 sorghum genotypes exhibiting large variations in physical and physiological traits. The objectives of this study were to: (i) develop and validate an image analysis-based approach for nondestructive measurement of chlorophyll for individual plants, (ii) investigate how the chlorophyll estimation could be improved by including other auxiliary variables including DAS (day after sowing) and SLW (specific leaf weight), and (iii) to evaluate the potential use of the high through phenotypic images as a rapid tool to estimate spatial distribution of chlorophyll concentration within sorghum.

\section{Materials and methods}

\subsection{Plant material and growth conditions}

Fifteen different sorghum genotypes (20 plants each, 300 plants total) were used in this study, and the goal was to create a large variation in plant leaf property to validate HTPP image-based measurement. The experiment was conducted at the Greenhouse Innovation Center of the University of NebraskaLincoln starting Jan 2019. Data collection occurred in April of 2019.

The temperature in the greenhouse was regulated between 25 and $27{ }^{\circ} \mathrm{C}$ during daytime and 20 $22{ }^{\circ} \mathrm{C}$ during the night time. Relative humidity was maintained at $\sim 60 \%$. The daily light intensity resulting from natural sunlight and the supplemental LED peaked at $\sim 350 \mu \mathrm{mol} / \mathrm{m}^{2} / \mathrm{s}$ photosynthetically active radiation. The supplemental LED had a photoperiod set to 12 hours. The pots used were $25.72 \mathrm{~cm}$ in diameter and $23.18 \mathrm{~cm}$ in height, with a capacity of $8.52 \mathrm{~L}$. The pot substrate was made by mixing Fafard germination soil and water. The visual differences between DAS were pronounced (Fig. 1). 


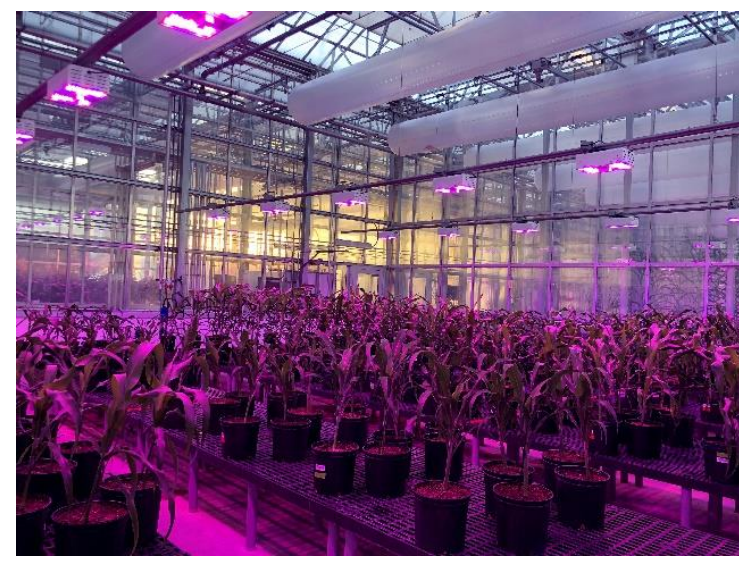

120 DAS

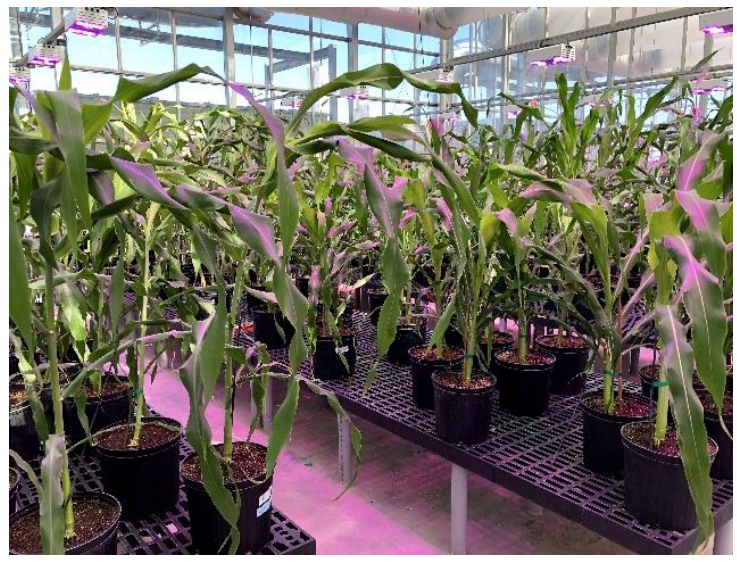

135 DAS

Figure. 1 Photos of the planted sorghum with different DAS (days after sowing).

The experiment was designed as a two-factorial design, replicated five times, with the water and nutrition regime as the two main factors. For the 20 plants in each genotype, 5 plants were randomly selected and assigned to one of the four treatment combinations: drought (D) and high nutrition condition (HN), drought (D) and low nutrition condition (LN), well-watered (HW) and high nutrition condition (HN), well-watered (HW) and low nutrition condition (LN). The estimated volumetric water content of soil for the drought group (maintain $5230 \mathrm{~g}$ of pot weight by adding water daily) was $30 \%$ and for the well-watered group was approximately $70 \%$ of field capacity. During the growth, the plants were watered everyday to the targeted soil water content. The plants were irrigated with two different nutrient solutions twice per week and high-nutrition regime and low-nutrition treatment were as shown in Table 1.

Table. 1 Composition of the nutrient solution to provide different levels of nutrition.

\begin{tabular}{|c|c|c|c|}
\hline Chemical & $\begin{array}{c}\text { High nutrition } \\
\mathrm{g} / \mathrm{L}\end{array}$ & $\begin{array}{c}\text { Low nutrition } \\
\mathrm{g} / \mathrm{L}\end{array}$ & $\begin{array}{c}\text { Concentration } \\
\mathrm{ml} / \mathrm{L}\end{array}$ \\
\cline { 1 - 3 } $\mathrm{KNO}_{3}$ & 82.15 & 8.21 & \multirow{2}{*}{8} \\
\cline { 1 - 3 } $\mathrm{Ca}\left(\mathrm{NO}_{3}\right)_{2} \cdot 2 \mathrm{H}_{2} \mathrm{O}$ & 118.07 & 11.81 & \multirow{2}{*}{8} \\
\cline { 1 - 3 } $\mathrm{KCl}$ & 0 & 46.13 & \multirow{2}{*}{8} \\
\hline $\mathrm{CaCl}_{2} \cdot 2 \mathrm{H}_{2} \mathrm{O}$ & 0 & 66.16 & \\
\hline $\mathrm{NH}_{4} \mathrm{H}_{2} \mathrm{PO}_{4}$ & 14.38 & 61.64 & \\
\hline $\mathrm{MgSO}_{4} \cdot 7 \mathrm{H}_{2} \mathrm{O}$ & 61.62 & 15.31 & \\
\hline $\mathrm{KH}_{2} \mathrm{PO}_{4}$ & 0 & \multicolumn{2}{|c}{} \\
\hline
\end{tabular}




\begin{tabular}{|c|c|c|c|}
\hline $\mathrm{H}_{3} \mathrm{BO}_{3}$ & 0.28 & 0.28 & \multirow{2}{*}{1} \\
\cline { 1 - 3 } $\mathrm{MnCl}_{2} \cdot 4 \mathrm{H}_{2} \mathrm{O}$ & 0.10 & 0.10 & \\
\hline $\mathrm{ZnSO}_{4} \cdot 7 \mathrm{H}_{2} \mathrm{O}$ & 0.06 & 0.06 & \\
\hline$\left(\mathrm{NH}_{4}\right)_{6} \mathrm{Mo}_{7} \mathrm{O}_{24} \cdot 4 \mathrm{H}_{2} \mathrm{O}$ & 0.12 & 0.12 & \\
\hline $\mathrm{CuSO}_{4} \cdot 5 \mathrm{H}_{2} \mathrm{O}$ & 0.05 & 0.05 & 1 \\
\hline $\mathrm{Fe}-\mathrm{EDTA}$ & 26.21 & 26.21 & \\
\hline
\end{tabular}

\subsection{High throughput imaging collection}

High throughput images were collected on the sorghums prior to destructive sampling of plant leaf tissues. The sampled leaves were under stresses that affects chlorophyll content. This greenhouse was equipped with a high-throughput plant phenotyping system (Scanalyzer 3D, LemnaTec GmbH, Aachen, Germany) (Ge et al., 2016). The research collected visible (RGB), hyperspectral, and fluorescence images by using three imaging chambers. The imaging modules and their main parameters in these chambers are shown in Table 2. The hyperspectral imaging chamber is illuminated by two banks of halogen lamps (35W, color temperature $2600 \mathrm{~K})$, located on the ceiling above the plant and the other on the wall behind the imaging system. The chambers are designed to permit the imaging of plants up to a nominal height of $2.5 \mathrm{~m}$. During test, the intact plants were loaded onto the conveyer belt and transported to conduct imaging scanning.

Table.2 Main parameters of the LemnaTec 3D Scanalyzer imaging system.

\begin{tabular}{|c|c|c|c|}
\hline Imaging chamber & Camera maker & Position & Key parameters \\
\hline Visible (RGB) & Basler & $\begin{array}{l}\text { Side, } \\
\text { Top }\end{array}$ & $\begin{array}{l}\text { Resolution: } 2454-2056 \text { pixels } 24 \text { bit } \\
\text { Spectral range: } 400-700 \mathrm{~nm}\end{array}$ \\
\hline $\begin{array}{l}\text { Steady state } \\
\text { fluorescence }\end{array}$ & Basler & $\begin{array}{l}\text { Side, } \\
\text { Top }\end{array}$ & $\begin{array}{l}\text { Excitation wavelength: } 400-500 \mathrm{~nm} \\
\text { Measured emission wavelength:500-750 nm } \\
\text { Resolution: } 1038 \text { - } 1390 \text { pixels } 24 \text { bit }\end{array}$ \\
\hline Hyperspectral & Headwall & Side & $\begin{array}{c}\text { Wavelength range: } 550-1750 \mathrm{~nm} \\
\text { Spectral bandwidth: } 5 \mathrm{~nm} \\
\text { number of bands: } 243 \\
\text { Spatial resolution: } 320 \text { pixel line width } \\
\text { Image formation: vertical scanning }\end{array}$ \\
\hline
\end{tabular}

\subsection{Sampling plant leaves for determination of phenotypic traits}


Crop development was monitored throughout the growing cycle. Plant sampling was conducted when roughly $80 \%$ of the sorghum plants were undergoing flowering. The measurements were performed only on the main tiller. After image acquisition, the plants were destructively measured for the determination of phenotypic traits as described below.

From each plant, the 3 leaf samples were chosen except flag leaf (which is leaf 1). Leaf 2, 3 and 4 from the plant were cut at the stem and immediately weighed for fresh weight. Leaf Area (LA) of leaf 2, 3 and 4 was determined with a leaf area meter (LI-3100C, LI-COR Biosciences, Lincoln, USA). Chlorophyll content was estimated with a portable chlorophyll concentration meter (MC-100, Apogee Instruments, Inc., Logan, UT). The MC-100 measures the chlorophyll (Chl) content as a fast, compact and easy approach. It was calibrated to measure chlorophyll concentration in leaves using the sensor's build-in sorghum calibration with unit of $\mathrm{Chl}$ was $\mu \mathrm{mol} / \mathrm{m}^{2}$. Three sampling areas of approximately $64 \mathrm{~mm}^{2}$ (circle with $9 \mathrm{~mm}$ diameter) were taken from the same leaf for the determination of chlorophyll. That is, every leaf was estimated at the tip, middle and base sections to account for inleaf variability, and the average of the nine spot measurements were regarded as the plant's chlorophyll content value from that plant. The harvested plant leaves were then placed in a walk-in oven at $50^{\circ} \mathrm{C}$ for 72 hours, followed by the measurement of dry weight.

\subsection{Phenotyping image processing and data analysis}

Image processing of the RGB, hyperspectral, and fluorescence images was done by using Matlab R2017a (MATLAB and Image Processing and Computer Vision Toolbox Release 2017a, The MathWorks, Inc., Natick, Massachusetts, United States). The major task of image processing was to extract plant pixels from RGB, hyperspectral, and fluorescence images from which image-based plant 
phenotypes can be derived.

In this research, chlorophyll concentration meter MC 100 measuring the amount of $\mathrm{Chl}$ in leaf 2, 3 and 4. However, the cameras captured images of the entire plant including all leaves and the stem. In order to match what the chlorophyll meter measure to the images, efforts were made to confine the analysis on leaves 2, 3 and 4 of each plant image only and calculate their projected area. In the present study, the specific leaf image is defined as the leaf image amount (for example, greenness of image) per total projected area ( pixel number).

\subsubsection{Visible imaging acquisition}

Ten 2454 x 2056 resolution RGB images were taken of every plant: ten side view images from every 36 degrees at a horizontal rotation. In order to compare the estimation between chlorophyll content with color features, image processing technique was used and the color components of red (R), green (G) and blue (B) in RGB space and hue (H), saturation (S) and intensity (I) in HSI space were determined. During the color analysis, the HSI space was calculated by using the RGB space to increase the contrast between plant region and background region. Color spaces RGB and HSI can be transformed from one to another easily as illustrated in 'equations (1) - (3)'. A schematic diagram of the image processing procedure is shown in Figure 2.

$$
\begin{aligned}
& \mathrm{H}=\arccos \left\{\frac{[(R-G)+(R-B)] / 2}{\left[(R-G)^{2}+(R-B)(G-B)\right]^{1 / 2}}\right\} \\
& \mathrm{S}=1-\frac{3}{(R+G+B)}[\min (R, G, B)] \\
& \mathrm{I}=\frac{1}{3}(R+G+B)
\end{aligned}
$$

Segmentation of these images was done by calculating a color index for each pixel and then using a threshold to derive a segmented image. The color index $3 * \mathrm{~S} /(\mathrm{H}+\mathrm{S}+\mathrm{I})$ (where $\mathrm{H}, \mathrm{S}$, and I denote the 
hue, saturation and intensity components) was found to be effective in transforming HSI images to a single band images, because this index emphasized the saturation component in HSI pixels, and minimized the effect of non-consistent illumination among different images. A universal threshold of 0.75 was used to segment plant pixels from background.

The resulting image is a binary image, using white and black to distinguish the plant and background regions, respectively. But the binary image was found to contain noise in the form of isolated noise as well as vertical stripes near the edge of the image. Since the frames of the chamber were located in a fixed position for all images from greenhouse, the stripes were eliminated by using the reference image. And then area opening operation was applied to remove the small objects that contains fewer than 200 pixels from the binary image.
a. Initial true color plant image
b. Convert Red, Green, Blue to
c. Thresholding with the color Hue, Saturation, Intensity index to binary image
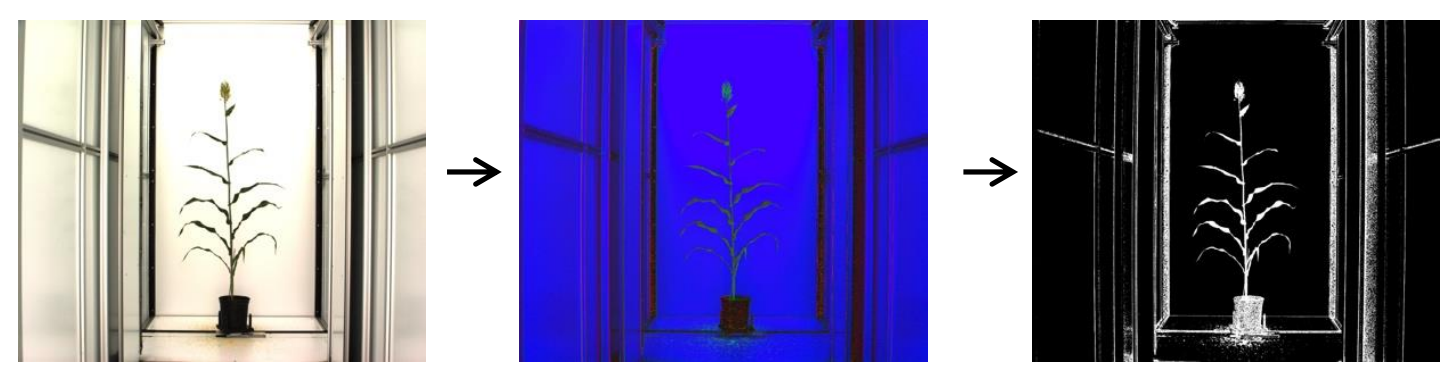

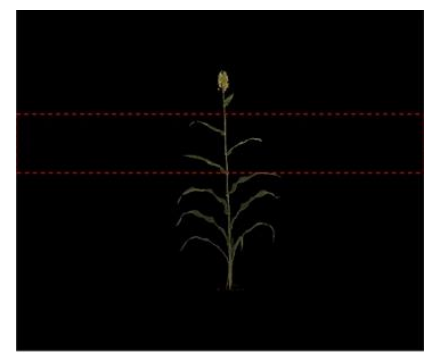

f. Extraction of the area with leaf 2,3 and 4

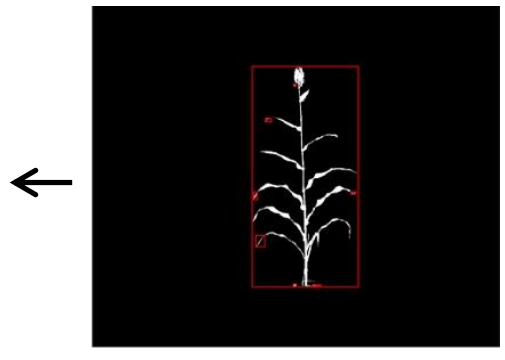

e. After region limitation

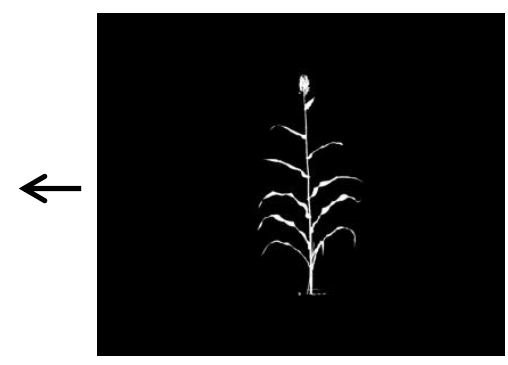

d. After the morphological opening and removing the vertical stripe using algorithm

Figure. 2 The sequential steps in segmentation of plant pixels from the background 
A feature-region-based image matching method was proposed, in order to match chlorophyll content from MC 100 in leaf 2, 3 and 4 more efficiently and accurately. From statistics, we evaluated this criterion (5 to 35\%) applied to all images to finally realize limitation of leaf 2,3 and 4 . In order to find an appropriate range, which contains the second leaf, the third leaf, and the fourth leaf, the random sampling method is used to infer the population parameters. The percentage of the position tall is recorded, which is the length from the top of the whole sorghum to the recorded position divided by the entire sorghum's height. The range is divided into several subranges, with a gap width of $5 \%$. If the position is located less than $2.5 \%$ tall, the recorded position will be 0 ; If the position is located between $2.5 \%$ and $7.5 \%$ tall, the recorded position will be $5 \%$; If the position is located between $7.5 \%$ and $12.5 \%$ tall, the recorded position will be $10 \%$. The majority of the percentages are concluded to indicate the positions in the population. For each image, two positions are recorded, the top position of the second leaf and the bottom position of the fourth leaf. In this experiment, 300 images are randomly sampled from 3000 images, with 300 sorghum samples in total and ten angles for each sample. Positions from sampling analysis suggest that the majority percentages for the second leaf's top position is $5 \%$ and the majority percentages for the bottom position of the fourth leaf is $35 \%$. Therefore, from statistics, we evaluated this criterion (5 to 35\%) applied to the entire dataset to finally realize limitation of leaf 2, 3 and 4 . It was determined the total height of the plant, and set the two boundaries at $5 \%$ and $35 \%$ of the total height as the specific region. The specific region which contained just the three leaves elements was limited and a new matrix was formed. Then we acquired the extraction of the area with leaf 2, 3 and 4 to calculate the H, S, I value respectively, and use the same limitation area to suit the original RGB image to acquire the R, G, B value. Specific leaf image 
of hue $(\mathrm{H})$ component was calculated as the total Hue value of image divided into the pixel number.

Specific leaf image of saturation (S), intensity (I), red (R), green (G) and blue (B) component are in the same way.

The total pixel count of the plant from ten side views were then averaged as plant Projected Area (PA, or equivalently, pixel count). The number of pixels inside the plant region was counted in each of the ten side views, and then averaged to give the projected shoot area. This is not the actual aboveground surface area but the average of the areas of the image projected in ten planes. There are many cases when a mature plant's leaves are overlapping, appearing behind one another in side view images (Golzarian et al., 2011). Figure 3 shows ten different binary images converted from RGB from 0 to 360 degree. The ten orthogonal views (ten side views from 36 rotational difference) provides a means of correction of plant area for those overlapping leaves, corrects for hidden areas in the other views and gives a robust representation of plant area overall.

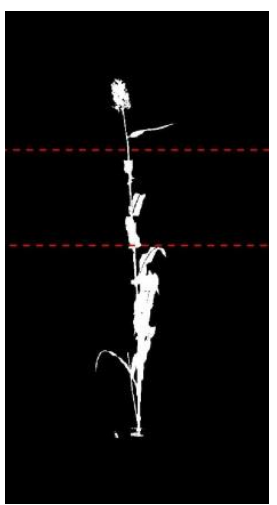

$0^{\circ}$

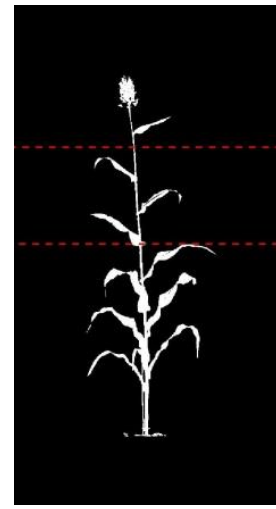

36

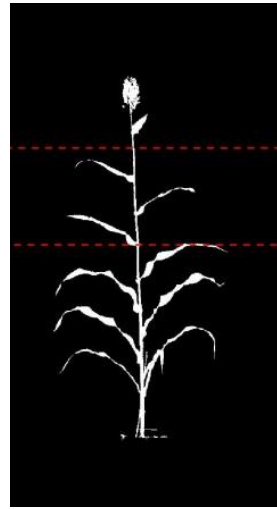

72

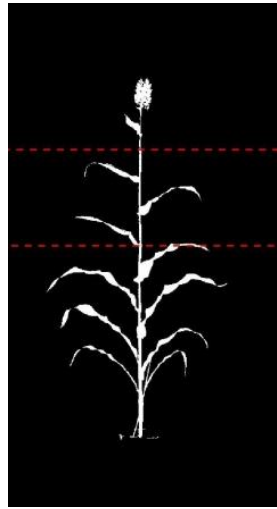

108

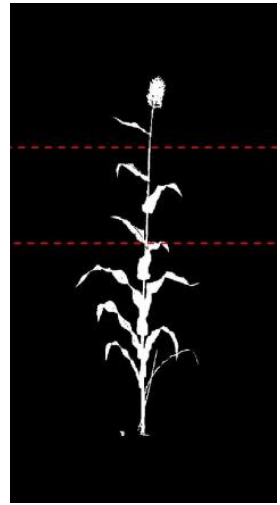

144 


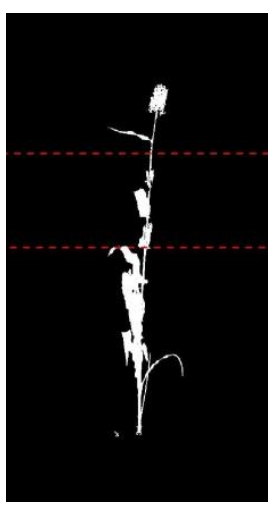

$180^{\circ}$

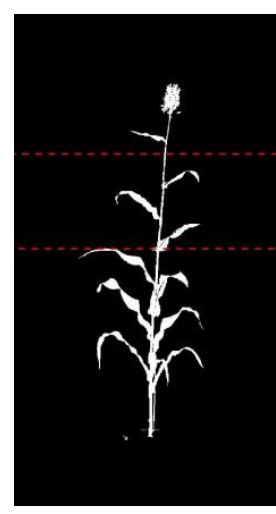

$216^{\circ}$

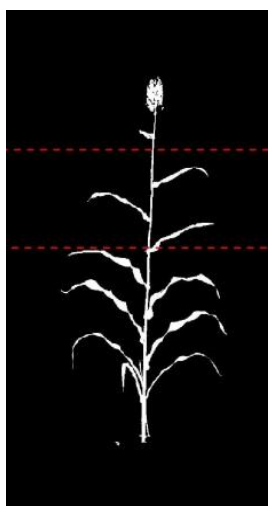

$252^{\circ}$

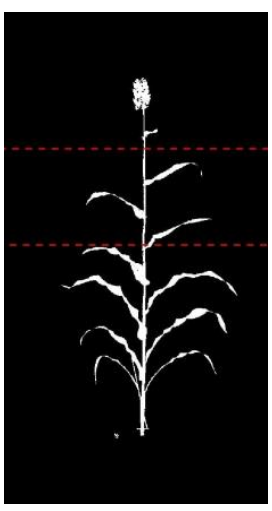

$288^{\circ}$

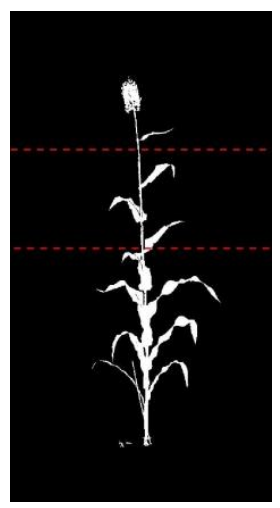

$324^{\circ}$

Figure. 3 Ten different binary images converted from RGB from 0 to 360 degree.

\subsubsection{Hyperspectral imaging acquisition}

The hyperspectral image chamber consisted of a total of 243 image bands, with a spectral sampling resolution of $5 \mathrm{~nm}$ per band. The raw image was captured in a BIL (Band Interleaved by Line) format to acquire and store the original hyperspectral data. Then the individual spectral bands were then extracted from the BIL file using a custom MATLAB function to build 243 hyperspectral images (Pandey et al., 2017). The plant image cubes were individually processed to extract the spectrum of pixel intensities. The segmentation of plant pixels in the hyperspectral images was achieved by making use of the rapid increase in reflectance of vegetation (Ni et al., 2020). The imagery was calibrated to reflectance (Jiang et al., 2020). The following procedures were used to process the hyperspectral images. First, intensity of images at band $35(705 \mathrm{~nm})$ and band $44(750 \mathrm{~nm})$ were used to normalize and generate new increased intensity; and then we got a function of the sum of those new intensities. Second, the new intensities were applied to separate the plant pixels well from the non-plant pixels in the hyperspectral images. A global threshold of 0.89 was used to get a binary mask from this image, where the higher values belonged to the plant pixels. This binary mask was then used for segmentation of each image bands in the hyperspectral cube. After removal of noise, the binary image was matched to the original image, and specific leaf image of hyperspectral image was calculated as the total 
hyperspectral value of image divided into the pixel number. The complete hyperspectral image processing procedure was shown in Figure 4.

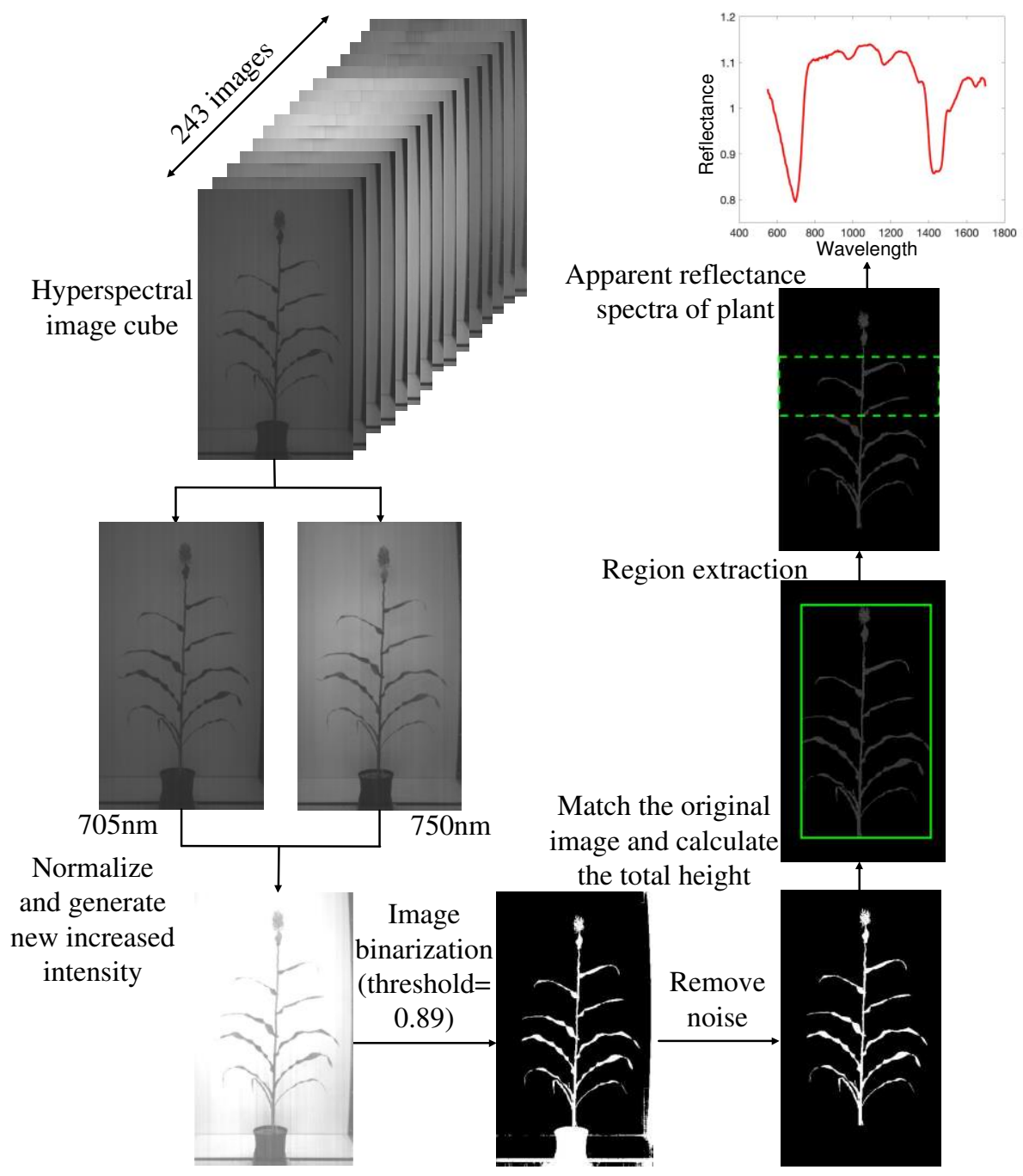

Figure. 4 Flowchart showing the steps in hyperspectral image analysis to obtain apparent reflectance spectra

The identification of plant stresses using hyperspectral imaging technology traditionally has been based upon changes in individual band intensities or changes in simple band ratios. In order to maximize the information reflected by the vegetation and minimize the impact of external factors, various hyperspectral indices were put forward and can detect subtle differences in physiological conditions and environmental stresses by their unique fine spectral characteristics, so these spectral indices have a broad application prospect in the inversion of chlorophyll content. The noninvasive 
optical methods all provided reliable estimates of relative leaf Chl. Empirical models to predict chlorophyll content are largely based on reflectance regions where the absorption is saturated at higher chlorophyll. Indices formulated with $705 \mathrm{~nm}$ and $750 \mathrm{~nm}$ bands would have higher accuracy in estimating chlorophyll content (Gitelson, et al. 1994). Reflectance index (Chl NDVI = (R750-R705)/ (R750+R705)) were commonly used in the literature (Richardson, 2002). According to every index of structure form and principle, hyperspectral index can be divided into the following types: normalized spectral index, ratio spectral index, and multi-band spectral index. Algorithms like the ratio vegetation index (RVI), the normalized difference vegetation index (NDVI), modified chlorophyll absorption ratio index (MCARI) have been used to measure canopy cover and chlorophyll content of plants. These ratios and algorithms are positively correlated to total chlorophyll levels in plants and each of them represents normalized spectral index, ratio spectral index, and multi-band spectral index. The most known and widely used vegetation index is NDVI. Despite NDVI, improved indices like RVI and MCARI have been developed in order to combine the advantage of different vegetation index and improve the linearity relationship with vegetation biophysical variables. Three indices NDVI [750,705], RVI[750,705], and MCARI[750,705 and 550] (Wu et al., 2008; Kim et al., 2011; Lu et al., 2019) were tested in this study with the following formulate:

$$
\begin{aligned}
& \mathrm{NDVI}=\frac{R_{750}-R_{705}}{R_{750}+R_{705}} \\
& \mathrm{RVI}=\frac{R_{750}}{R_{705}} \\
& \mathrm{MCARI}=\left(\left(\mathrm{R}_{750}-\mathrm{R}_{705}\right)-0.2 *\left(\mathrm{R}_{750}-\mathrm{R}_{550}\right)\right) *\left(\mathrm{R}_{750} / \mathrm{R}_{705}\right)
\end{aligned}
$$

\subsubsection{Fluorescence imaging acquisition}

Fluorescence imaging captures the image that the red band is mainly emitted from photosystem. With 
this system, various fluorescence signals could be obtained. For each region of interest, the fluorescence parameter values of all pixels within the area were averaged. Many different fluorescence parameters were used to characterize the various aspects of photosynthetic performance comprehensively.

Once chlorophyll fluorescence images were obtained, chlorophyll concentration of the entire plant was analyzed. For sorghum, the area of the entire plant was estimated using region of interest pixel numbers, and was used to monitor plant growth. A threshold value of 0.13 was determined to effectively segment plant pixels from the background. The fluorescence image of the plant from 0,72 , 144,216 , to 288 degree side views were then averaged as plant projected area. A schematic diagram of the fluorescence image processing procedure was shown in Figure 5. Specific leaf image of fluorescence image was the ratio of the total fluorescence value of image divided and the pixel number.

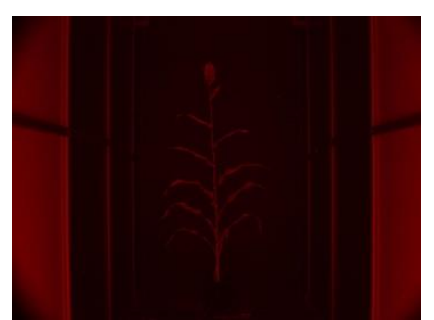

a. Initial fluorescence plant image

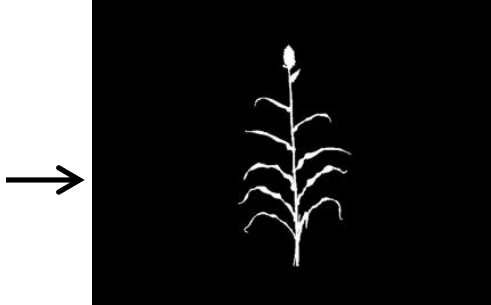

b. Thresholding with the color index to binary image

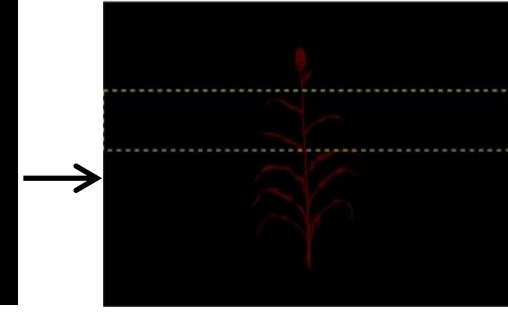

c. Extraction of the area with leaf 2,3 and 4

Figure. 5 Process flow of image processing steps used in the extraction of plant's projected chlorophyll content from the fluorescence images.

\subsubsection{Data analysis}

From the visible image, primary colors red (R), green $(\mathrm{G})$ and blue $(B)$, was recorded. Spectral parameters such as hue $(\mathrm{H})$, saturation $(\mathrm{S})$ and luminosity $(\mathrm{L})$ were estimated from RGB values. Specific leaf image was calculated by dividing the total component of image by total pixel number.

Hyperspectral and fluorescence image was processed in the same way. Specific leaf weight (SLW) is 
the oven-dry mass, divided by its one-sided area of fresh leaf (unit, $\mathrm{g} \mathrm{cm}^{-2}$ ).

In this analysis, DAS (days after sowing) is measured from the date of planting. The visual appearances were confirmed by DAS, because DAS represent the growth stage development. Previous research reported that the first period occurring in seeding stage matched with Chl's slow rise. The second critical period occurred in active jointing-booting growth stage and matched with Chl's fast increase. The third period is filling to maturing stage matched with Chl's slow decrease (Ali et al., 2015; Earl et al., 1999). DAS also showed a significant $(\mathrm{p}<0.01)$ positive correlation with the macronutrient content (Zandonadi et al., 2016). Therefore, chlorophyll content could be written as a linear form of DAS and high-throughput image. The MC 100 value has already been found to provide the most accurate estimation of chlorophyll content in good correlation with leaf chlorophyll content extracted through organic solvent method (Padilla et al., 2018).

For each type of imaging, the 300 plants were split into two groups: 240 plants $(80 \%)$ for model calibration and the other $60(20 \%)$ for independent model validation. The split was done such that the different sorghum genotypes and the treatment levels for both water and nutrient were presented in the calibration and validation set. The following statistic was calculated using software $\mathrm{R}$ for model evaluation: Coefficient of Determination $\left(R^{2}\right)$ between for MC 100-measured and model-fitted values. Akaike Information Criterion (AIC) was used to select the regression models that balance the size of the model and the predictive power. When choosing the best model from a set of alternative models, the smallest AIC is criterion.

To comprehensively include all the variables acquired form visible, hyperspectral and fluorescence images, partial least squared regression (PLSR) was used to model the sorghum plant 
chlorophyll content from image data. PLSR is constructed to illustrate the vegetation indexes' effect from different imaging techniques on the chlorophyll content. The variables, including hue, saturation, intensity, R, G, B, fluorescence, NDVI, RVI, MCARI. We split the 300 plants into two groups: 240 plants $(80 \%)$ for model calibration and the other $60(20 \%)$ for independent model validation. The split was done such that the treatment levels for both water stress and nutrient stress experiments were equally presented in the calibration and validation set. To find out the model with the best performance, 5-fold cross-validation is applied to the training dataset, and therefore, the model with minimum mean square error is preferred. The following statistics were evaluated for model performance: coefficient of determination $\left(R^{2}\right)$, root mean squared error (RMSE, Equation 7), and ratio of performance to deviation (RPD, Equation 8) between the lab-measured and model-estimated plant chlorophyll content.

$$
\begin{gathered}
R M S E=\sqrt{\frac{1}{N} \times \sum_{i}\left(\widehat{y}_{l}-y_{i}\right)^{2}} \\
R P D=\frac{S D(y)}{R M S E}
\end{gathered}
$$

$\mathrm{N}$ is the number of plants in the calibration or validation set (300); $y_{i}$ and $\widehat{y}_{l}$ are the lab-measured and model-predicted values, respectively; SD and mean are the standard deviation and mean of the lab-measured values.

RPD is the factor by which the prediction accuracy has been increased compared to using the mean of the original data. We classified RPD values as follows: RPD $<1.0$ indicates very poor model/predictions and their use is not recommended; RPD between 1.0 and 1.4 indicates poor model/predictions where only high and low values are distinguishable; RPD between 1.4 and 1.8 indicates fair model/predictions which may be used for assessment and correlation; RPD values between 1.8 and 2.0 indicates good model/predictions where quantitative predictions are possible; 
RPD between 2.0 and 2.5 indicates very good, quantitative model/predictions, and RPD $>2.5$ indicates excellent model/predictions.

\section{Results and discussion}

\subsection{Correlation of visible image with chlorophyll content}

The linear model seems to be the best of those considered so far, justifying its common use in the literature. For our data, the linear method for estimating chlorophyll content as a linear function of visible image was used. In these models the chlorophyll content (reading of MC 100 chlorophyll concentration meter) was the dependent variable, while DAS and the visible image were defined to be independent variables. For instance, the linear model is a function with the equation of Chl $=a_{0}+a_{1} R$ $+\mathrm{a}_{2} \mathrm{DAS}$, where $\mathrm{R}$ is the specific leaf image of red value from visible image.

The values of the three primary colors were linearly correlated to obtain the characteristic RGB models as described in figure 5. Among the values of three primary colors of the leaves of sorghum, $\mathrm{R}$ and $\mathrm{G}$ were negatively correlated with the chlorophyll content measured by chlorophyll content meter MC 100. It can be seen from figure 6 that in contrast to R and G, an increasing trend of mean brightness with chlorophyll content was observed with B color chromate. A good agreement between the value of $\mathrm{G}$ and chlorophyll content was observed, while value of R and B were poorly correlated with chlorophyll content which indicates the more relevance of $\mathrm{G}$ color than $\mathrm{R}$ and $\mathrm{B}$ for determining the chlorophyll content in regenerated plants by using a single color component. The regression between chlorophyll data obtained from MC 100 values, R, G, B pixels and DAS showed a linear relationship $\left(\mathrm{R}^{2}=0.56,0.64\right.$ and 0.48$)$. The regression results indicated the spectral characteristics of crop which absorbed light in red and blue regions, while reflected light in green region. 

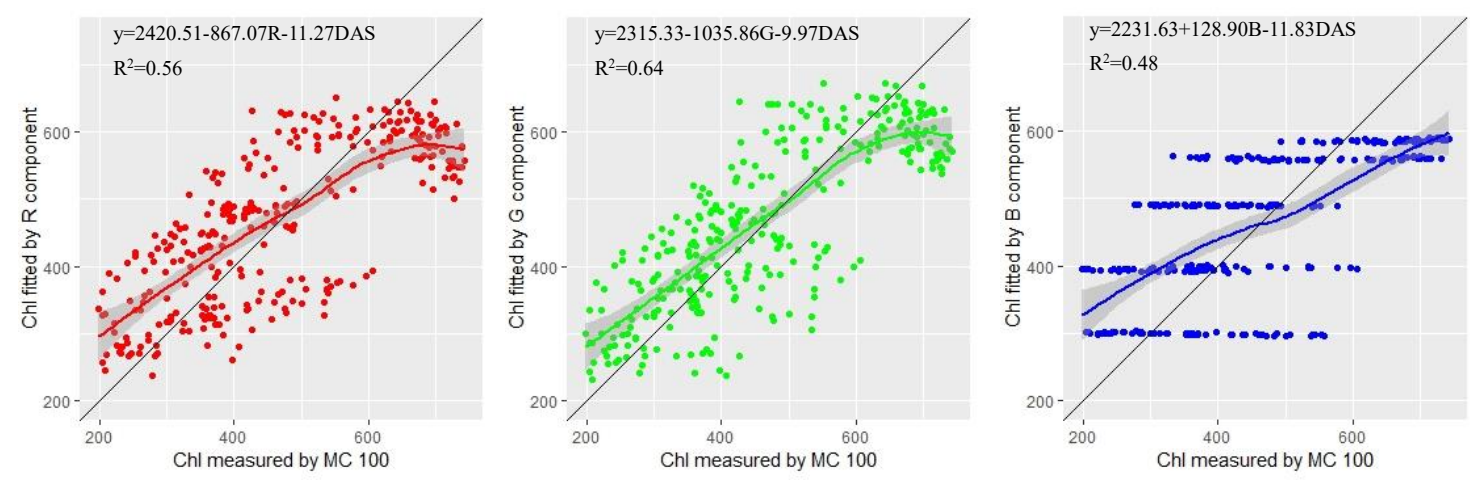

Figure. 6 The correlations between the Chl values of measured by MC100 with predicted by R, G and B component and DAS.

From the visible image, primary colors R (red), G (green) and B (blue), was recorded. Spectral parameters such as $\mathrm{H}$ (hue), $\mathrm{S}$ (saturation) and I (intensity) were estimated from RGB values. The $\mathrm{H}$, S, and I parameters were chosen from color space because it corresponds better to how people experience color than the RGB parameter set (Stevens, 2002; Mack et al., 2018). Image information such as, hue, saturation and intensity color coordinates were also considered to study the relationship of color coordinates with chlorophyll content. Using the H, S and I components, the visible "greenness" of three leaves can be quantified and can be compared. A significant correlation was observed between the S parameter with chlorophyll content, while weaker correlation was observed with I parameter (Figure.7). Leaves hue of image analysis showed liable correlation with leaf chlorophyll content measured after pigment extraction, but this linear relationship was worse than saturation.
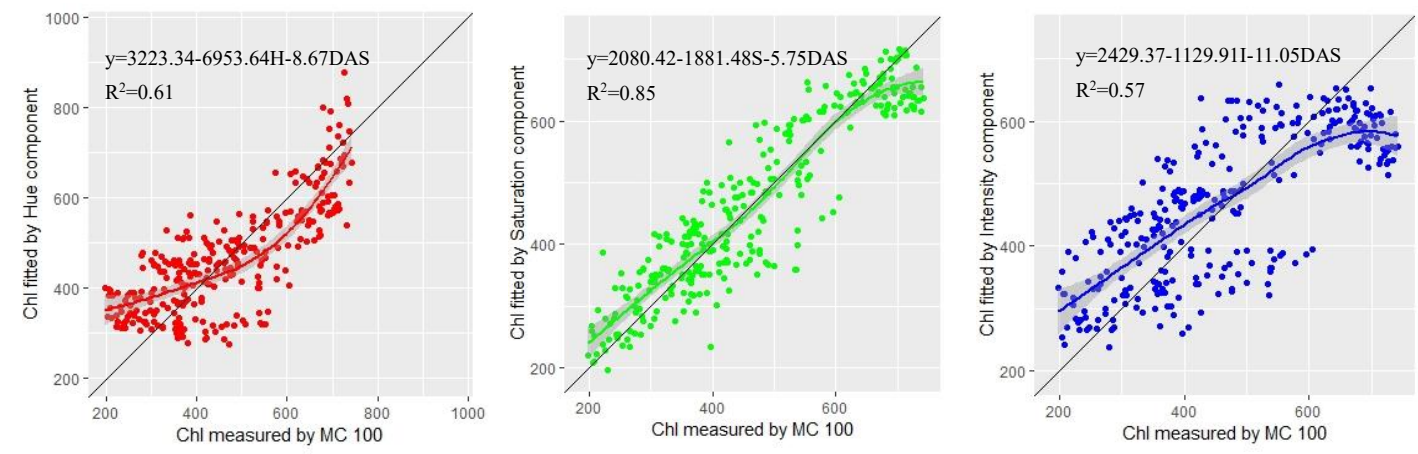
Figure. 7 The correlations between the values of hue, saturation and intensity with chlorophyll content

For Chl estimation in sorghum, figure 7 showed the correlation between hue, intensity and MC 100 reading $\left(R^{2}=0.61\right.$ and 0.57 , respectively).Saturation gave a better Chl detection results with $R^{2}=$ 0.85. As with Chl, HSI color model is found to achieve better fitting than RGB color model.

\subsection{Correlation of hyperspectral image with chlorophyll content}

Figure 8 showed significant relationships between the Chl predicted by vegetation indexes of hyperspectral images and MC 100 measured Chl. In fact, the obtained results are similar for the three indexes. On the other hand, the proposed method achieved better $\mathrm{R}^{2}$ to outperform liner regression method in predicting Chl content.
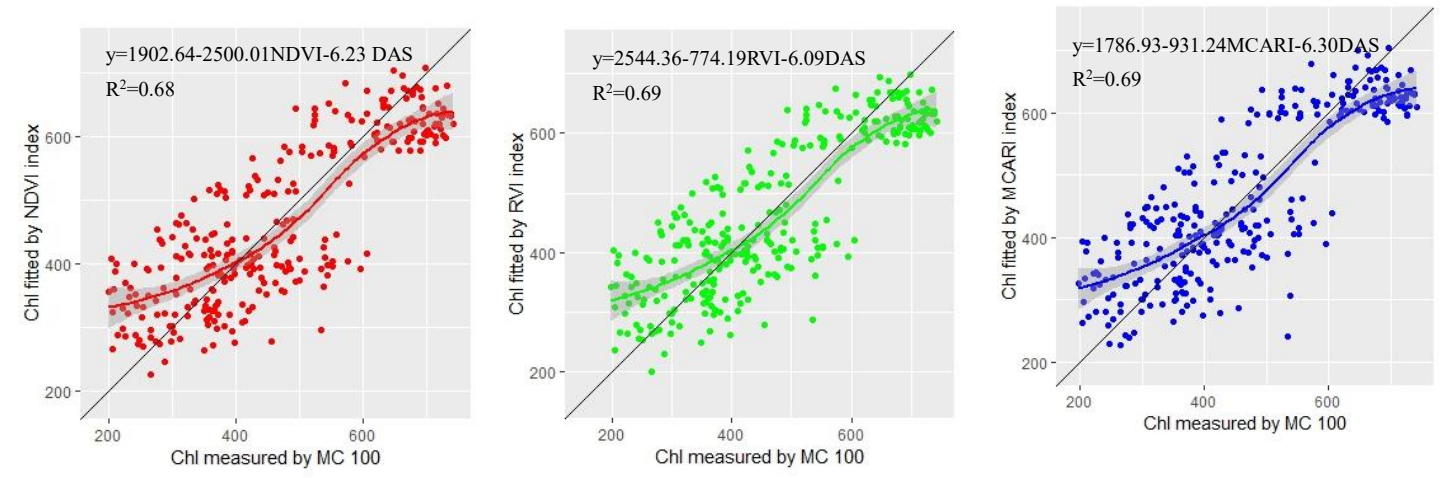

Figure. 8 The correlations between the values of hyperspectral image with chlorophyll content

Figure 8 showed the correlation between NDVI, RVI, MCARI and MC 100 reading $\left(\mathrm{R}^{2}=0.68\right.$, 0.69 and 0.69 , respectively).RVI and MCARI gave a slightly better Chl detection results with $\mathrm{R}^{2}=0.75$. It can be seen that normalized spectral index, ratio spectral index, and multi-band spectral index can predict the chlorophyll content well.

\subsection{Correlation of fluorescence image with chlorophyll content}

Data were subjected to simple regression analysis, with value from MC 100 chlorophyll meter as the 
dependent variable and greenness chlorophyll content form fluorescence image as the independent variable. The result was shown in figure 9 , and the square of the correlation coefficient of regressions was 0.69 . By non-destructively detecting the chlorophyll content and chlorophyll distribution of sorghum, it could provide a support for greenhouse crop growth evaluation and precision management

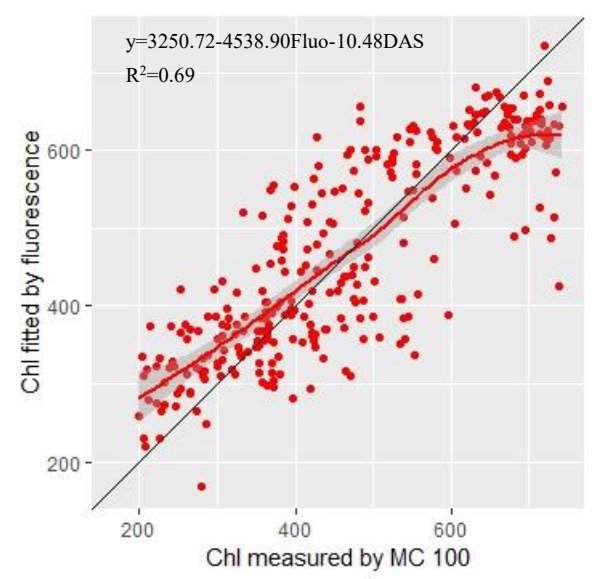

Figure. 9 The correlations between the values of fluorescence image with chlorophyll content

\subsection{Correlation of different images with chlorophyll content}

PLSR was developed to model and predict by using the selected vegetation indices computed from different imaging data to predict chlorophyll content for sorghum plants. Hue, saturation, intensity, R, G, B, fluorescence, NDVI, RVI, MCARI, are first used, and then DAS (day after sowing) are gradually taken into consideration. Firstly, the models without DAS information and SLW information are considered. The component number of 9 suggests the best result with all variables. To get the necessity for all variables included, the importance of all vegetation indexes is also examined. It shows that all vegetation indexes play remarkable roles in constructing the model because it promises the model with a minimum mean square error. Then, the models with DAS information are considered. The component number of 8 guarantees the best result with all variables considered. Based on the absolute 
value for coefficients for each variable, the importance for each vegetation index is sorted. The larger the absolute value of the coefficient is, the more indispensable the corresponding variable is. Therefore, it indicated that the hue information is not necessary for constructing the PLSR regression with the component number of 9 . The statistics to evaluations for each model are listed in table 3 .

Table. 3 Test results of using the selected vegetation indices computed from different imaging data to predict chlorophyll content for sorghum plants

\begin{tabular}{|c|c|c|c|c|c|c|}
\hline & & & $\begin{array}{l}\text { Calibration Dataset } \\
\text { with 5-fold validation }\end{array}$ & $\begin{array}{c}\text { Calibration } \\
\text { Dataset }\end{array}$ & $\begin{array}{c}\text { Validation } \\
\text { Dataset }\end{array}$ & $\begin{array}{l}\text { Entire } \\
\text { Dataset }\end{array}$ \\
\hline \multirow{3}{*}{$\begin{array}{c}\text { Model } 1 \\
\text { (without DAS) }\end{array}$} & \multirow{3}{*}{$\begin{array}{l}\text { with/without } \\
\text { feature reduction }\end{array}$} & $\mathrm{R}^{2}$ & 0.84 & 0.86 & 0.90 & 0.87 \\
\hline & & RMSE & 60.70 & 57.53 & 51.34 & 55.39 \\
\hline & & RPD & 2.49 & 2.62 & 3.16 & 2.77 \\
\hline \multirow{6}{*}{$\begin{array}{c}\text { Model } 2 \\
\text { (with DAS) }\end{array}$} & \multirow{3}{*}{$\begin{array}{l}\text { without feature } \\
\text { reduction }\end{array}$} & $\mathrm{R}^{2}$ & 0.87 & 0.88 & 0.92 & 0.89 \\
\hline & & RMSE & 54.68 & 51.89 & 45.54 & 49.89 \\
\hline & & RPD & 2.76 & 2.90 & 3.57 & 3.08 \\
\hline & \multirow{3}{*}{$\begin{array}{l}\text { with feature 'Hue' } \\
\text { reduction }\end{array}$} & $\mathrm{R}^{2}$ & 0.87 & 0.88 & 0.92 & 0.90 \\
\hline & & RMSE & 54.60 & 51.61 & 45.37 & 49.64 \\
\hline & & RPD & 2.76 & 2.92 & 3.58 & 3.09 \\
\hline
\end{tabular}

Table 3 shows that PLSR regression models guarantee that the $\mathrm{R}^{2}$ is greater than 0.84 and RPD is larger than 2.49, which indicates that PLSR regression models provide an accurate way to predict chlorophyll's content.

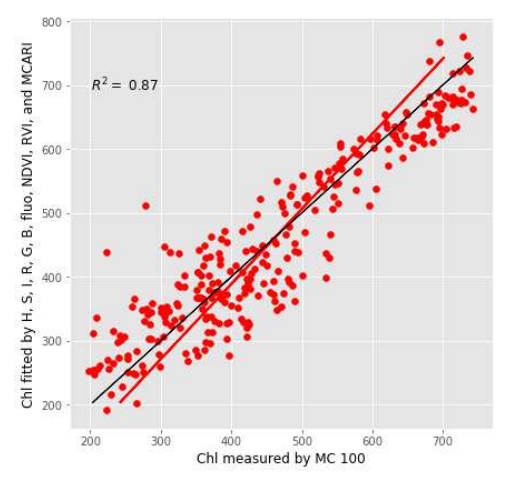

(a) Model 1 (without DAS)

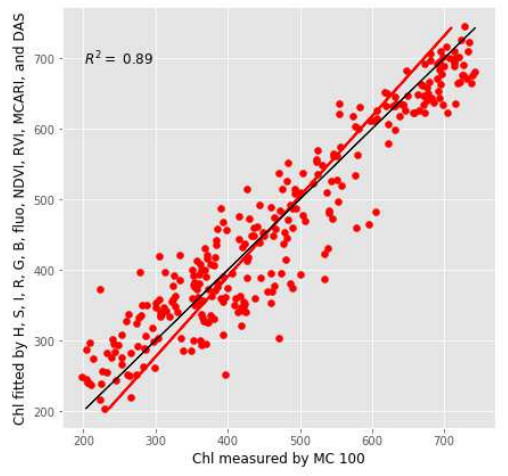

(b) Model 2 (with DAS)

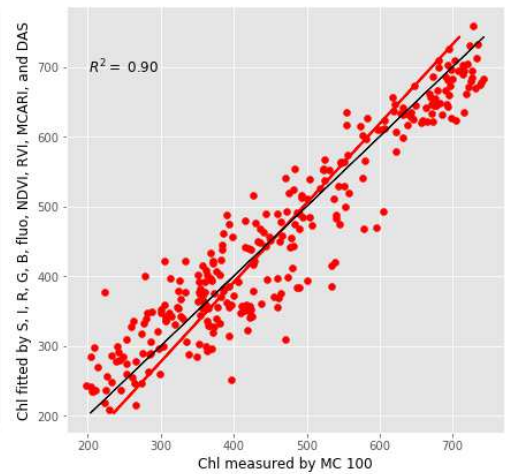

(c) Model 2 (with DAS and feature 'Hue' reduction)

Figure. 10 The correlations between the selected vegetation indices computed from different imaging data with chlorophyll content 
It can be seen form figure 10 that the PLSR Model 2 (with DAS and feature 'Hue' reduction) has improved the $\mathrm{R}^{2}$ compared with the PLSR Model 1 (without DAS) and PLSR Model 2 (with DAS). Comparing the performance among different models, it can be concluded that (1). When more useful features are considered, the performance of the model becomes better. (2). Reducing unnecessary features in the model, the performance of the model becomes better.

\subsection{Discussion}

In order to reduce the bias, we put forward a predictive model based on the specific leaf weight (SLW). SLW and single-leaf apparent photosynthesis (AP) have been shown to be positively correlated in field studies (Buttery et al., 1981). Sampling for SLW as a predictor of AP is not widely employed because it takes much time and energy and thus is not practical for evaluating large populations (Thompson et al., 1996). SLW is defined as the leaf dry weight per one-side area and it is sensitive to plant nitrogen status, light climate and several other stresses (Field et al., 1986), so it is a key variable involved with or related to physiological processes occurring in the functioning of canopies. The observations across the images showed that chlorophyll content can be estimated as a multiple linear function of color component and SLW (Table 4). Therefore, chlorophyll content could be written as a linear form of image, DAS and SLW, i.e. Chl $=\mathrm{b}_{0}+\mathrm{b}_{1} \mathrm{R}+\mathrm{b}_{2} \mathrm{DAS}+\mathrm{b}_{3} \mathrm{SLW}$.

Table.4 Estimation error for different multiple linear models used to estimate chlorophyll content for various

\begin{tabular}{|c|c|l|c|c|}
\hline Imaging technology & Component & \multicolumn{1}{|c|}{ Regression } & $\mathrm{R}^{2}$ & $\mathrm{AIC}$ \\
\hline \multirow{3}{*}{ Visible image } & \multirow{3}{*}{$\mathrm{R}$} & $\mathrm{y}=\mathrm{a}_{0}+\mathrm{a}_{1} \mathrm{R}+\mathrm{a}_{2} \mathrm{DAS}$ & 0.56 & 3630 \\
\cline { 3 - 6 } & $\mathrm{y}=\mathrm{b}_{0}+\mathrm{b}_{1} \mathrm{R}+\mathrm{b}_{2} \mathrm{DAS}+\mathrm{b}_{3} \mathrm{SLW}$ & 0.77 & 3440 \\
\cline { 2 - 6 } & \multirow{2}{*}{$\mathrm{G}$} & $\mathrm{y}=\mathrm{a}_{0}+\mathrm{a}_{1} \mathrm{G}+\mathrm{a}_{2} \mathrm{DAS}$ & 0.64 & 3569 \\
\cline { 2 - 6 } & $\mathrm{y}=\mathrm{b}_{0}+\mathrm{b}_{1} \mathrm{G}+\mathrm{b}_{2} \mathrm{DAS}+\mathrm{b}_{3} \mathrm{SLW}$ & 0.79 & 3413 \\
\cline { 2 - 6 } & \multirow{2}{*}{$\mathrm{B}$} & $\mathrm{y}=\mathrm{a}_{0}+\mathrm{a}_{1} \mathrm{~B}+\mathrm{a}_{2} \mathrm{DAS}$ & 0.48 & 3680 \\
\cline { 3 - 6 } & $\mathrm{y}=\mathrm{b}_{0}+\mathrm{b}_{1} \mathrm{~B}+\mathrm{b}_{2} \mathrm{DAS}+\mathrm{b}_{3} \mathrm{SLW}$ & 0.70 & 3513 \\
\cline { 2 - 6 } & $\mathrm{H}$ & $\mathrm{y}=\mathrm{a}_{0}+\mathrm{a}_{1} \mathrm{H}+\mathrm{a}_{2} \mathrm{DAS}$ & 0.61 & 3589 \\
\hline
\end{tabular}




\begin{tabular}{|c|c|c|c|c|}
\hline & & $\mathrm{y}=\mathrm{b}_{0}+\mathrm{b}_{1} \mathrm{H}+\mathrm{b}_{2} \mathrm{DAS}+\mathrm{b}_{3} \mathrm{SLW}$ & 0.67 & 3539 \\
\hline & \multirow{2}{*}{$\mathrm{S}$} & $\mathrm{y}=\mathrm{a}_{0}+\mathrm{a}_{1} \mathrm{~S}+\mathrm{a}_{2} \mathrm{DAS}$ & 0.85 & 3309 \\
\hline & & $\mathrm{y}=\mathrm{b}_{0}+\mathrm{b}_{1} \mathrm{~S}+\mathrm{b}_{2} \mathrm{DAS}+\mathrm{b}_{3} \mathrm{SLW}$ & 0.88 & 3252 \\
\hline & \multirow{2}{*}{ I } & $\mathrm{y}=\mathrm{a}_{0}+\mathrm{a}_{1} \mathrm{I}+\mathrm{a}_{2} \mathrm{DAS}$ & 0.57 & 3621 \\
\hline & & $\mathrm{y}=\mathrm{b}_{0}+\mathrm{b}_{1} \mathrm{I}+\mathrm{b}_{2} \mathrm{DAS}+\mathrm{b}_{3} \mathrm{SLW}$ & 0.77 & 3440 \\
\hline \multirow{6}{*}{ Hyperspectral image } & \multirow{2}{*}{ NDVI } & $\mathrm{y}=\mathrm{a}_{0}+\mathrm{a}_{1} \mathrm{NDVI}+\mathrm{a}_{2} \mathrm{DAS}$ & 0.68 & 3488 \\
\hline & & $\mathrm{y}=\mathrm{b}_{0}+\mathrm{b}_{1} \mathrm{NDVI}+\mathrm{b}_{2} \mathrm{DAS}+\mathrm{b}_{3} \mathrm{SLW}$ & 0.77 & 3395 \\
\hline & \multirow{2}{*}{ RVI } & $\mathrm{y}=\mathrm{a}_{0}+\mathrm{a}_{1} \mathrm{RVI}+\mathrm{a}_{2} \mathrm{DAS}$ & 0.69 & 3475 \\
\hline & & $\mathrm{y}=\mathrm{b}_{0}+\mathrm{b}_{1} \mathrm{RVI}+\mathrm{b}_{2} \mathrm{DAS}+\mathrm{b}_{3} \mathrm{SLW}$ & 0.77 & 3383 \\
\hline & \multirow{2}{*}{ MCARI } & $\mathrm{y}=\mathrm{a}_{0}+\mathrm{a}_{1} \mathrm{MCARI}+\mathrm{a}_{2} \mathrm{DAS}$ & 0.69 & 3471 \\
\hline & & $\mathrm{y}=\mathrm{b}_{0}+\mathrm{b}_{1} \mathrm{MCARI}+\mathrm{b}_{2} \mathrm{DAS}+\mathrm{b}_{3} \mathrm{SLW}$ & 0.78 & 3375 \\
\hline \multirow{2}{*}{ Fluorescence image } & & $\mathrm{y}=\mathrm{a}_{0}+\mathrm{a}_{1}$ Fluo $+\mathrm{a}_{2} \mathrm{DAS}$ & 0.69 & 3519 \\
\hline & & $\mathrm{y}=\mathrm{b}_{0}+\mathrm{b}_{1}$ Fluo $+\mathrm{b}_{2} \mathrm{DAS}+\mathrm{b}_{3} \mathrm{SLW}$ & 0.79 & 3404 \\
\hline
\end{tabular}

As the multiple linear model based on DAS and SLW proved to be better than the multiple linear models we considered, we compared our proposed model with the linear model described in table 4 .

Since the resulting square of the correlation coefficient from two multiple linear models were given in table 3. Multiple linear model based on DAS and SLW produced significantly larger $\mathrm{R}^{2}$, so the correlation of regression model introduced SLW has significantly improved. Similarly low values of error function (AIC), thereby confirming the model tested on DAS and SLW can satisfactorily estimate chlorophyll content. It can be seen from table 3 that the maximum correlation coefficient of $\mathrm{R}^{2}=0.88$ was obtained with multiple linear regression based on DAS and SLW of S. The multiple linear regression based on DAS of $\mathrm{S}$ revealed the correlation coefficient of $\mathrm{R}^{2}=0.85$. The analysis also substantiated the potential use of $\mathrm{H}, \mathrm{S}$ and I than the primary colors $\mathrm{R}, \mathrm{G}$ and $\mathrm{B}$. For hyperspectral index, NDVI, RVI, MCARI all shows that the adjustment of phenotypic image values for SLW greatly increases the accuracy of the prediction. The higher $\mathrm{R}^{2}$ values and lower AIC values confirmed the best fitted model after introducing parameter SLW that estimates the chlorophyll content (Table 4). Multiple linear regression model with MC 100 value as the dependent variable, and greenness chlorophyll content form fluorescence image and SLW as the independent variables gave the good 
estimation of chlorophyll content in leaves of sorghum. This study was to test hypothesis that specific leaf weight (SLW) appears to be one of the factors determining leaf chlorophyll content under different water and nutrition conditions. The influence of SLW on chlorophyll content and an improved simple method to determine chlorophyll content of sorghum by MC 100 chlorophyll meter was seen from table 4.

CHL could be estimated quite satisfactorily with the selected vegetation indices computed from different imaging data to predict chlorophyll content for sorghum plants (Table 5). It can be seen $\mathrm{R}^{2}$ range from 0.87 to 0.92 ; whereas RPD is bigger than 2.77). Therefore, the linear combination of saturation, intensity, R, G, B, fluorescence, NDVI, RVI, MCARI, DAS, and SLW, suggests the best regression model, as shown in figure 11 . The red dots represent all samples, and the blue line is the prediction line from the model. It can be seen form table 5 that the PLSR Model 3 (after adding DAS) has improved the $\mathrm{R}^{2}$ and RPD.

Table.5 Test results of using the selected vegetation indices computed from different imaging data and SLW to predict chlorophyll content for sorghum plants

\begin{tabular}{|c|c|c|c|c|c|c|}
\hline & & & $\begin{array}{l}\text { Calibration Dataset } \\
\text { with 5-fold validation }\end{array}$ & $\begin{array}{c}\text { Calibration } \\
\text { Dataset }\end{array}$ & $\begin{array}{c}\text { Validation } \\
\text { Dataset }\end{array}$ & $\begin{array}{l}\text { Entire } \\
\text { Dataset }\end{array}$ \\
\hline \multirow{6}{*}{$\begin{array}{c}\text { Model } 3 \\
\text { (with DAS and } \\
\text { SLW) }\end{array}$} & \multirow{3}{*}{$\begin{array}{l}\text { without feature } \\
\text { reduction }\end{array}$} & $\mathrm{R}^{2}$ & 0.87 & 0.88 & 0.92 & 0.90 \\
\hline & & RMSE & 54.40 & 51.56 & 45.61 & 49.59 \\
\hline & & RPD & 2.77 & 2.93 & 3.56 & 3.09 \\
\hline & \multirow{3}{*}{$\begin{array}{c}\text { with feature 'Hue' } \\
\text { reduction }\end{array}$} & $\mathrm{R}^{2}$ & 0.87 & 0.88 & 0.92 & 0.90 \\
\hline & & RMSE & 54.29 & 51.46 & 45.41 & 49.49 \\
\hline & & RPD & 2.78 & 2.93 & 3.58 & 3.10 \\
\hline
\end{tabular}




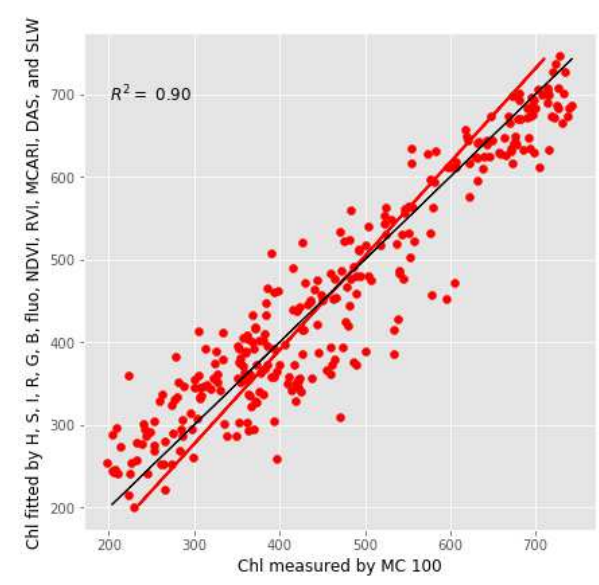

(a) Model 2 (with DAS and SLW)

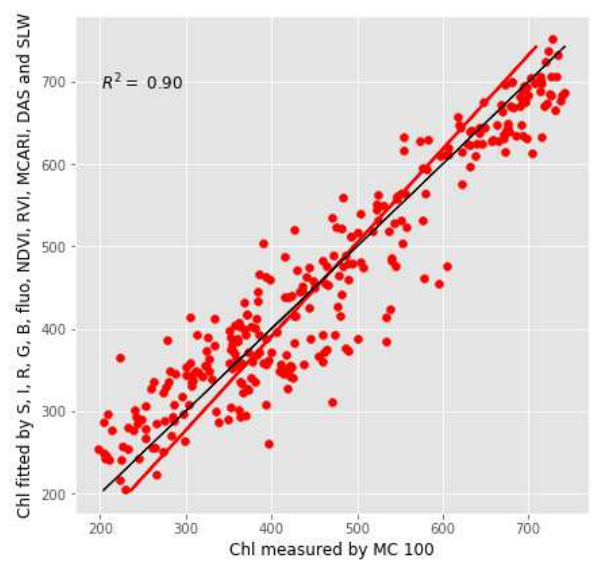

(c) Model 2 (with DAS, SLW and feature 'Hue' reduction)

Figure. 11 The correlations between the selected vegetation indices computed from different imaging data and SLW with chlorophyll content

Overall, these results confirmed the idea that the SLW, which was used as an additional input for predicting chlorophyll content in high throughput phenotypic image, plays a vital role in reducing the error. This can be seen in tables determination coefficient of the model was increased by involving SLW. Using SLW as parameters could help to improve the prediction accuracy of the model.

As can be seen from table 3 , the values of error function used to minimize the differences between the experimental and predicted data, all the models based on DAS and SLW exhibited high $\mathrm{R}^{2}$ value and low values of AIC, thereby confirming satisfactorily chlorophyll content for models tested. This difference between the linear regression and multiple linear regression might have been due to introducing variable SLW, one of indicators of leaf thickness. The influence of leaf thickness on regression model contributed to better estimation of chlorophyll content by the chlorophyll meter. Leaf thickness changes according to leaf age and growth environment (Gratani et al., 2000; Knapp et al., 1998). Also, it has been demonstrated that reflectance increases and transmittance decrease with an increase in leaf thickness (Yamamoto et al., 2002). Thus, it is hypothesized that leaf thickness is one of the factors that determines chlorophyll content under different conditions (water conditions, and nutrition treatment). 
Increasing SLW may improve leaf apparent photosynthesis. Pettigrew reported that plants grown under dryland production had a $12 \%$ increase in SLW, and he speculated that these leaves may have been denser or thicker than leaves of irrigated plants (Pettigrew, 2004). In response to drought, waterstressed plants had 12\% more chlorophyll than well watered plants (Da et al., 2011). Campbell, R. J analyzed the relationship between the SPAD-501 (SPAD) meter and total extracted chlorophyll (TChl) for leaf sets grown under greenhouse and field conditions, and found big difference. It has been suggested that the disparity in the models between experiments may partly be due to differences in leaf thickness. Field-grown leaves are typically thicker than greenhouse-grown leaves, and this is supported by the higher SLW values for the field-grown leaves (Campbell et al., 1990). The estimation of Chl with the SPAD over time may be confounded by changes in SLW. Peng et al also demonstrated that thick leaves increased SPAD readings and thicker leaves (i.e. higher SLW) absorbed red light more than infrared light in leaves with similar chlorophyll content on the basis of leaf area (Peng et al., 1993). SLW is in general an indicator of leaf thickness and the degree of mesophyll development within a leaf blade. The extent of mesophyll development largely determines the photosynthetic capacity of a leaf. Thus, SLW can potentially be used as an indirect measure of the photosynthetic characteristics of a leaf (Jurik, 1986).

The possibility exists for why there was higher chlorophyll content in stressed plants: droughtstressed plants had smaller and thicker leaves, causing higher chlorophyll concentration. Well-watered plants may have translocated nutrient resources to new growing areas due to the fact that irrigated plants had an extended growing season resulting in lower chlorophyll readings (Esfahani et al., 2008). The SLW data revealed stressed plants had thicker and denser leaves, which may have led to more 
chlorophyll per leaf and consequently SLW is an important contributing variable for predicting chlorophyll.

The objective of the present study is to develop a generalized method to estimate the chlorophyll content of sorghum from its high throughput phenotypic image. We have developed a method that significantly reduces the bias in chlorophyll content estimation of stressed plants. We have demonstrated that models that uses mixed variables of plant image's greenness and SLW achieves this reduction and therefore the method we proposed can be used to compute more accurately the chlorophyll content of sorghum regardless of whether or not they are water and nutrition stressed.

As easy method for determining the chlorophyll content is using portable chlorophyll meter. Even in vivo chlorophyll determination can be made using SPAD-502 meter that makes nondestructive and rapid measurements of leaf chlorophyll based on spectral transmittance properties of leaves (Madeira et al., 2003). However, chlorophyll meter provides that data only in arbitrary units rather than the actually amounts of chlorophyll per unit of leaf tissue.

Recently the image processing techniques have been used for remote sensing studies concerning plant monitoring projects. It is precisely because of by far easier acquisition of images and the facility of being available as real-time database that image processing has been captured the attention of researchers as alternative strategy. However, reports on the in-vivo analysis of chlorophyll content from high throughput phenotyping facility cannot be found in the literature. The use of the imaging techniques in vivo characterization of leaf chlorophyll content at the plant level would provide information about the usefulness of the technology in non-destructive phenotyping, stress detecting, ranking, and selection of plants. 
It seems that high throughput phenotypic image provides a simple, rapid, and nondestructive method to estimate the leaf chlorophyll concentration, and could be reliably exploited to predict the exact stress in sorghum. The present work demonstrated the potential for real time estimation of chlorophyll content by high throughput image analysis and DAS.

There is no facility available for the direct measurement of SLW. Currently, SLW is calculated as the ratio of leaf dry weight to fresh leaf area. Although there is not an instrument to directly and accurately measure leaf thickness, the measurement of leaf thickness could be nondestructive and relatively easier than the measurement of SLW. As technology advances, a device for measuring leaf thickness could be developed and incorporated into the image analysis to provide chlorophyll content more accurately.

\section{Conclusions}

In this study, a robust and accurate method has been developed for rapid and noninvasive determination of chlorophyll content of leaves of sorghum using visible, hyperspectral and fluorescence based image analysis. The correlation relationship was improved by the spectral properties combination of DAS and SLW. It can be seen that adjustment of phenotypic image values for SLW increases the accuracy of the prediction. An image analysis method based on SLW may be an alternate choice for the real time prediction of chlorophyll content of plants. The potential of the imaging system in predicting chlorophyll has been discussed. It is concluded that imaging techniques can be a powerful tool for low-cost, nondestructive and high-throughput analysis of chlorophyll concentration.

\section{Declarations}




\section{Ethics approval and consent to participate}

Not applicable.

\section{Consent for publication}

Not applicable.

\section{Availability of data and materials}

The datasets generated and analyzed during the current study are available from the corresponding author on reasonable request.

\section{Competing interests}

The authors declare that they have no competing interests.

\section{Funding}

While working as a visiting scholar at the University of Nebraska-Lincoln, Huichun Zhang was supported by Jiangsu modern agricultural machinery equipment and technology demonstration and extension project (Grant No. NJ2020-18), Six Talent Peaks Project in Jiangsu Province (Grant No. NY-058), Qinglan Project Foundation of Jiangsu Province (Grant No. 201615, 20193), and 333 Project of Jiangsu Province (Grant No. 20186).

\section{Author's contributions}

Huichun Zhang led the study and analyzed the data. Abbas Atefi, Nuwan Wijewardane and Suresh Thapa collected the data. Xinyan Xie processed the image data. Huichun Zhang and Yufeng Ge interpreted the results. Huichun Zhang drafted the manuscript. Yufeng Ge significantly edited the 
manuscript.

\section{Acknowledgements}

The authors are grateful to the staff members at Greenhouse Innovation Center of the University of

Nebraska-Lincoln for their assistance in experiment design.

\section{References}

Ali, A. M., Thind, H. S., Sharma, S., 2015. Site-Specific Nitrogen Management in Dry Direct-Seeded Rice Using Chlorophyll Meter and Leaf Colour Chart. Pedosphere, 72-81.

Andrianto, H., Suhardi, Faizal, A. 2017. Measurement of chlorophyll content to determine nutrition deficiency in plants:

A systematic literature review. In Proceedings of the 2017 International Conference on Information Technology Systems and Innovation (ICITSI), Bandung, Indonesia, 23-24 October 2017:392-397.

Buttery, B. R., Buzzell, R. I., Findlay, W. I., 1981. Relationships among photosynthetic rate, bean yield and other characters in field-grown cultivars of soybean. Canadian Journal of Plant Science, 61(2), 190-197.

Campbell, R. J., Mobley, K. N., Marini, R. P., Pfeiffer, D. G., 1990. Growing conditions alter the relationship between SPAD-501 values and apple leaf chlorophyll. HortScience, 25(3), 330-331.

Chawade A, Ham J V, Blomquist H, et al. 2019. High-Throughput Field-Phenotyping Tools for Plant Breeding and Precision Agriculture. Agronomy, 9(5):258.

Da Costa, V. A., Cothren, J. T., 2011. Drought effects on gas exchange, chlorophyll, and plant growth of 1methylcyclopropene treated cotton. Agronomy journal, 103(4), 1230-1241.

Esfahani, M., Abbasi, H. A., Rabiei, B., Kavousi, M., 2008. Improvement of nitrogen management in rice paddy fields using chlorophyll meter (SPAD). Paddy and Water Environment, 6(2), 181-188. 
Earl, H. J., Tollenaar, M., 1999. Using chlorophyll fluorometry to compare photosynthetic performance of commercial maize (Zea mays L.) hybrids in the field. Field Crops Research, 61(3):201-210.

Fahlgren, N., Feldman, M., Gehan, M.A., Wilson M.S., Shyu, C., Bryant, D.W., Hill, S.T., McEntee, C.J., Warnasooriya, S.N., Kumar, I., Ficor, T., Turnipseed, S., Gilbert, K.B., Brutnell T.P., Carrington, J.C., Mockler, T.C., Baxter, I., 2015. A Versatile Phenotyping System and Analytics Platform Reveals Diverse Temporal Responses to Water Availability in Setaria. Molecular Plant, 6, 5

Feng, H., Chen, G., Xiong, L., Liu, Q., Yang, W., 2017. Accurate digitization of the chlorophyll distribution of individual rice leaves using hyperspectral imaging and an integrated image analysis pipeline. Front plant science, 8:1238.

Field, C. H., Mooney, H. A. 1986. Photosynthesis--nitrogen relationship in wild plants. In On the Economy of Plant Form and Function: Proceedings of the Sixth Maria Moors Cabot Symposium, Evolutionary Constraints on Primary Productivity, Adaptive Patterns of Energy Capture in Plants, Harvard Forest, August 1983. Cambridge [Cambridgeshire]: Cambridge University Press, c1986

Ge, Y., Bai, G., Stoerger, V., Schnable, J. C., 2016. Temporal dynamics of maize plant growth, water use, and leaf water content using automated high throughput RGB and hyperspectral imaging. Computers \& Electronics in Agriculture, 127:625-632.

Gitelson, A., Merzlyak, M, N. 1994. Spectral Reflectance Changes Associated with Autumn Senescence of Aesculus hippocastanum L. and Acer platanoides L. Leaves. Spectral Features and Relation to Chlorophyll Estimation. Journal of Plant Physiology, 143(3):286-292

Golzarian, M. R., Frick, R. A., Rajendran, K., Berger, B., Roy, S., Tester, M., Lun, D. S., 2011. Accurate inference of shoot biomass from high-throughput images of cereal plants. Plant methods, 7(1), 2. 
Gratani, L., Bombelli, A., 2000. Correlation between leaf age and other leaf traits in three Mediterranean maquis shrub species: Quercus ilex, Phillyrea latifolia and Cistus incanus. Environmental and experimental botany, 43(2), 141153.

Jespersen, D., Zhang, J., Huang, B., 2016. Chlorophyll loss associated with heat-induced senescence in bentgrass. Plant Science, $249,1-12$.

Jiang H., Jiang X., Ru Y., Wang J., Xu L., \& Zhou H. 2020. Application of hyperspectral imaging for detecting and visualizing leaf lard adulteration in minced pork. Infrared Physics \& Technology, 110, 103467.

Jin, X. L., Zarco-Tejada, P. J., Schmidhalter, U., Reynolds, M. P., Hawkesford, M. J., Varshney, R. K., Yang, T., Nie, C. W., Li, Z. H., Ming, B., Xiao, Y. G., Xie, Y. D., Li, S. K., 2020. High-Throughput Estimation of Crop Traits: A review of ground and aerial phenotyping platforms. IEEE Geoscience and Remote Sensing Magazine, 7

Jurik, T. W., 1986. Temporal and spatial patterns of specific leaf weight in successional northern hardwood tree species. American Journal of Botany, 73(8), 1083-1092.

Kim, Y., Glenn, D. M., Park, J., Ngugi, H. K., \& Lehman, B. L., 2011. Hyperspectral image analysis for water stress detection of apple trees. Computers and Electronics in Agriculture, 77(2), 155-160.

Knapp, A. K., Carter, G. A., 1998. Variability in leaf optical properties among 26 species from a broad range of habitats. American journal of botany, 85(7), 940-946.

Lu, B., He, Y., Dao, P. D., 2019. Comparing the Performance of Multispectral and Hyperspectral Images for Estimating Vegetation Properties. IEEE Journal of Selected Topics in Applied Earth Observations and Remote Sensing.

Mack, J., Schindler, F., Rist, F., 2018. Semantic labeling and reconstruction of grape bunches from 3D range data using a new RGB-D feature descriptor. Computers and Electronics in Agriculture, 155:96-102.

Madeira, A. C., Ferreira, A., de Varennes, A., Vieira, M. I., 2003. SPAD meter versus tristimulus colorimeter to estimate 
chlorophyll content and leaf color in sweet pepper. Communications in soil science and plant analysis, 34(17-18),

2461-2470.

Mahmoodi, Khazaei, J., Vahdati, K., 2013. Chlorophyll content estimation using image processing technique. World Applied ences Journal.

Majer, P., Sass, L., Horváth, G. V., Hideg, É., 2010. Leaf hue measurements offer a fast, high-throughput initial screening of photosynthesis in leaves. Journal of plant physiology, 167(1), 74-76.

Ni C., Li Z., Zhang X., Sun X., Huang Y., Zhao L., Zhu T., Wang D. 2020. Online Sorting of the Film on Cotton Based on Deep Learning and Hyperspectral Imaging. Ieee Access, 8: 93028-93038.

Padilla, F. M., de Souza, R., Peña, T., Gallardo, M., Gimenez, C., Thompson, R., 2018. Different responses of various chlorophyll meters to increasing nitrogen supply in sweet pepper. Frontiers in plant science, 9, 1752.

Pandey, P., Ge, Y., Stoerger, V., 2017. High Throughput in vivo analysis of plant leaf chemical properties using hyperspectral imaging. Frontiers in Plant science, $8,1348$.

Peng, S., Garcia, F. C., Laza, R. C, Cassman, K.G., 1993 Adjustment for specific leaf weight improves chlorophyll meter's estimation of rice leaf nitrogen concentration. Agron J 85:987 - 990

Pettigrew, W.T., 2004. Physiological consequences of moisture deficit stress in cotton. Crop Sci. 44:1265 - 1272.

Richardson A D, Duigan S P, Berlyn G P. 2002. An evaluation of noninvasive methods to estimate foliar chlorophyllcontent. New Phytologist, 153(1): 185-194.

Roitsch, T., Cabrera-Bosquet, Llorenç, Fournier, A., Ghamkhar, K., Jiménez-Berni, José, Pinto, F., 2019. Review: new sensors and data-driven approaches - a path to next generation phenomics. Plant Science, 282,2-10

Schuerger, A. C., Capelle, G. A., Di Benedetto, J. A., Mao, C., Thai, C. N., Evans, M. D., Stryjewski, E. C., 2003. Comparison of two hyperspectral imaging and two laser-induced fluorescence instruments for the detection of zinc 
stress and chlorophyll concentration in bahia grass (Paspalum notatum Flugge.). Remote sensing of environment, 84(4), 572-588.

Stevens, R. T., 2002. Computer Graphics Dictionary. Charles River Media, Inc.

Thompson, J. A., Schweitzer, L. E., Nelson, R. L., 1996. Association of specific leaf weight, an estimate of chlorophyll, and chlorophyll concentration with apparent photosynthesis in soybean. Photosynthesis research, 49(1), 1-10.

Wanneng Yang, Hui Feng, Xuehai Zhang, Jian Zhang, John H. Doonan, William David Batchelor, Lizhong Xiong, Jianbing Yan. Crop phenomics and high-throughput phenotyping: past decades, current challenges and future perspectives. Molecular Plant, 2020, 13, $187-214$.

Wu, C., Niu, Z., Tang, Q., Huang, W., 2008. Estimating chlorophyll content from hyperspectral vegetation indices: Modeling and validation. Agricultural and forest meteorology, 148(8-9), 1230-1241.

Yadav, S. P., Ibaraki, Y., Gupta, S. D., 2010. Estimation of the chlorophyll content of micropropagated potato plants using rgb based image analysis. Plant Cell Tissue \& Organ Culture, 100(2), 183-188.

Yamamoto, A., Nakamura, T., Adu-Gyamfi, J. J., \& Saigusa, M., 2002. Relationship between chlorophyll content in leaves of sorghum and pigeonpea determined by extraction method and by chlorophyll meter (SPAD-502). Journal of Plant Nutrition, 25(10), 2295-2301.

Zandonadi, C. H. S., Albuquerque, C. J. B., Freitas, R. S. D., 2016. Chlorophyll index (SPAD) and macronutrients relation and productive performance of sorghum hybrids in different sowing dates. Australian journal of crop science, 10(4):546-555. 


\section{Figures}

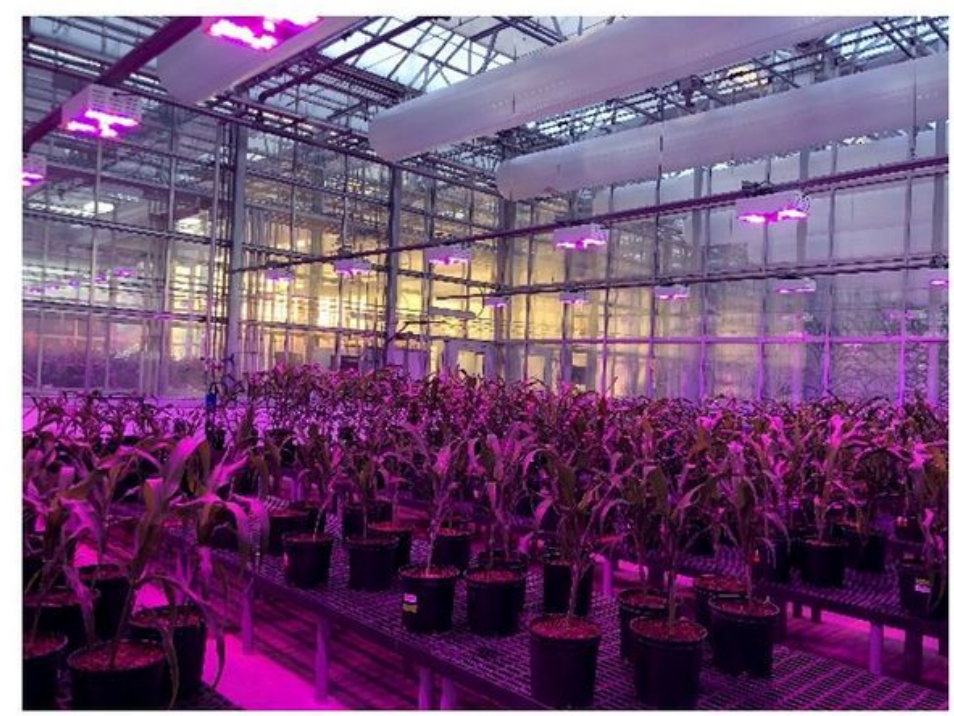

120 DAS

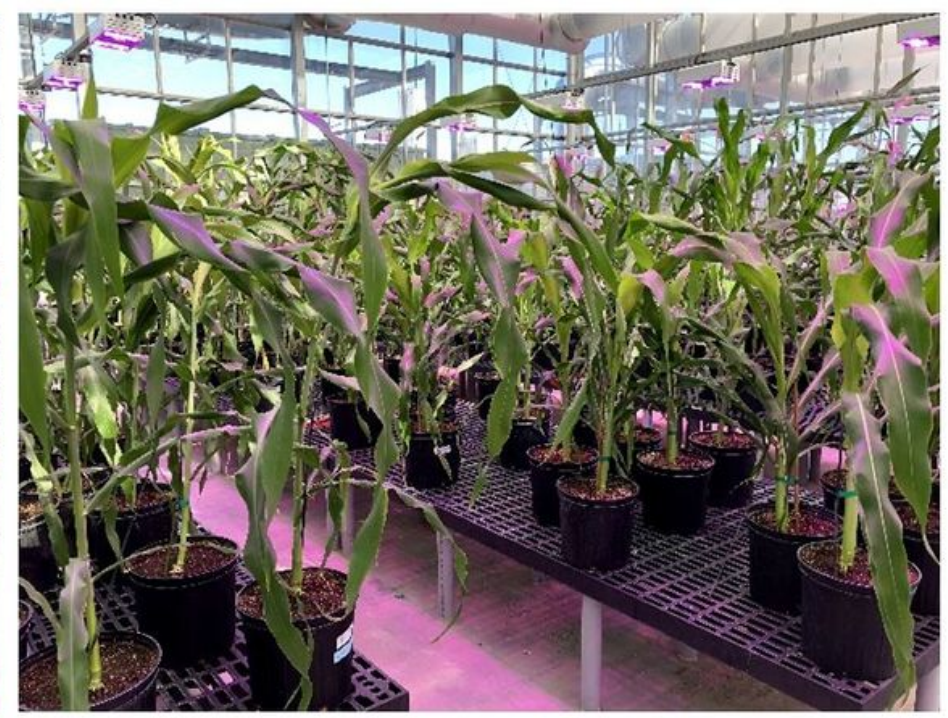

135 DAS

\section{Figure 1}

Photos of the planted sorghum with different DAS (days after sowing). 
a. Initial true color plant image

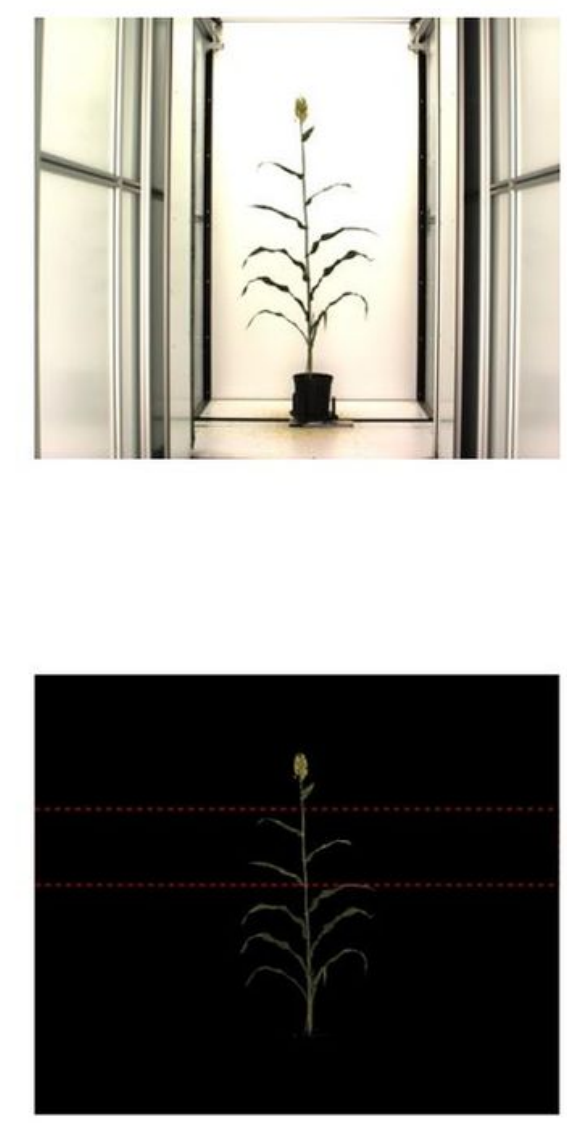

f. Extraction of the area with leaf 2,3 and 4 b. Convert Red, Green, Blue to Hue, Saturation, Intensity
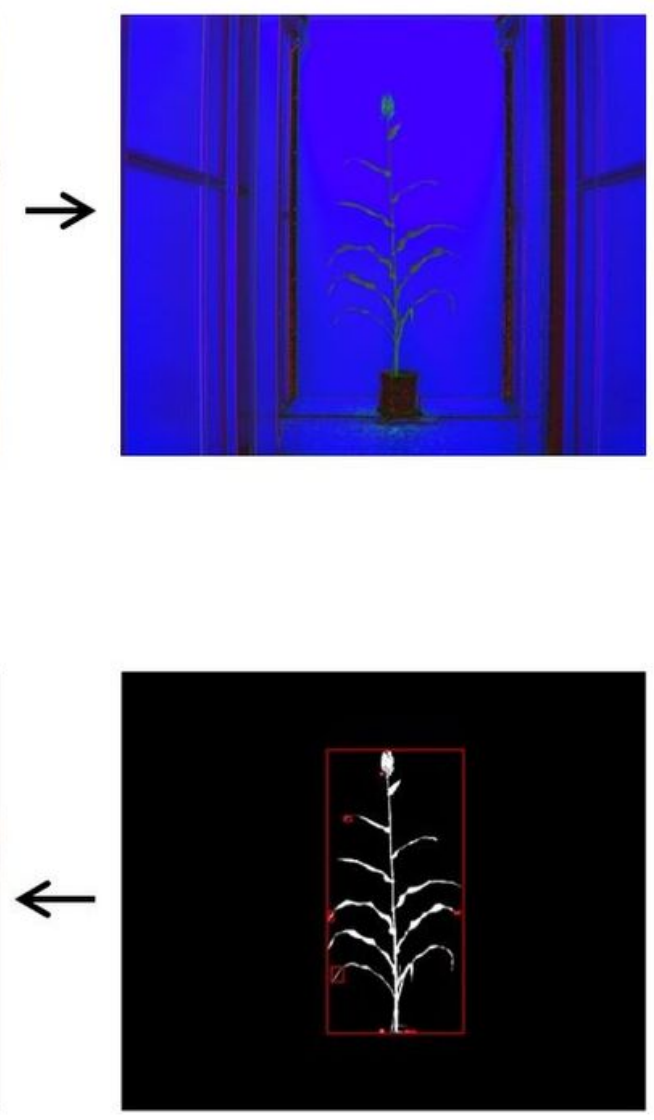

e. After region limitation
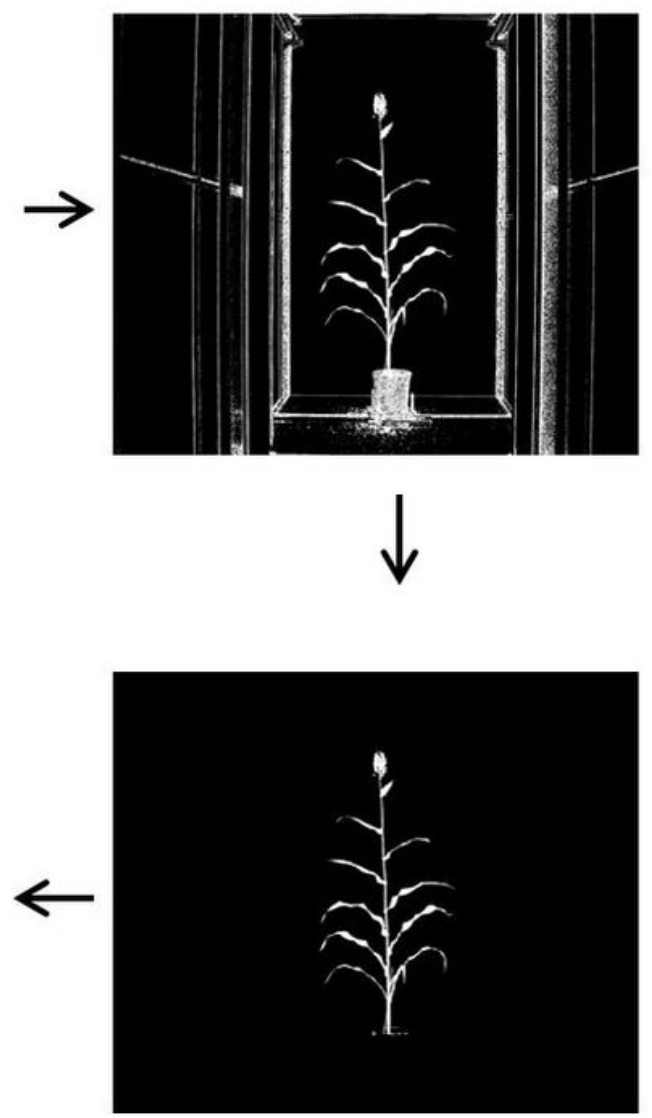

d. After the morphological opening and removing the vertical stripe using algorithm

\section{Figure 2}

The sequential steps in segmentation of plant pixels from the background 


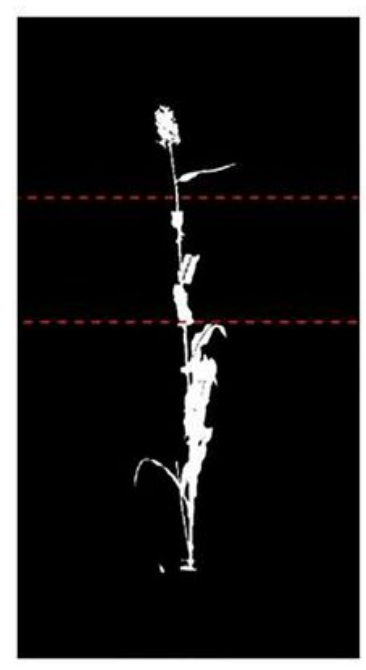

0

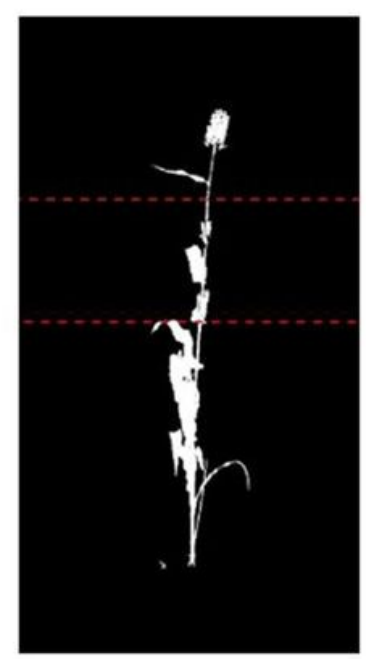

180

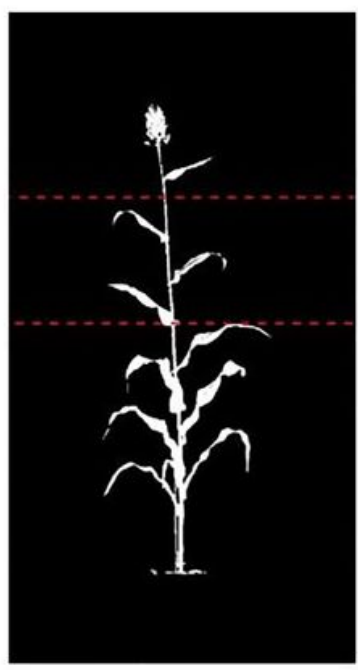

$36^{\circ}$

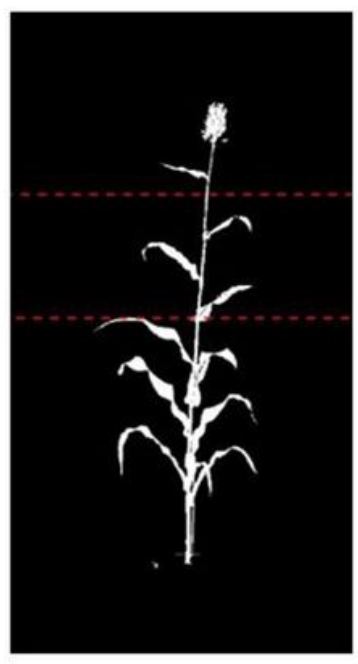

$216^{\circ}$

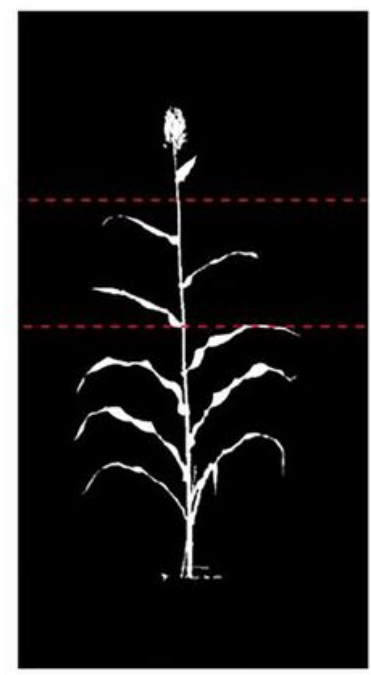

72

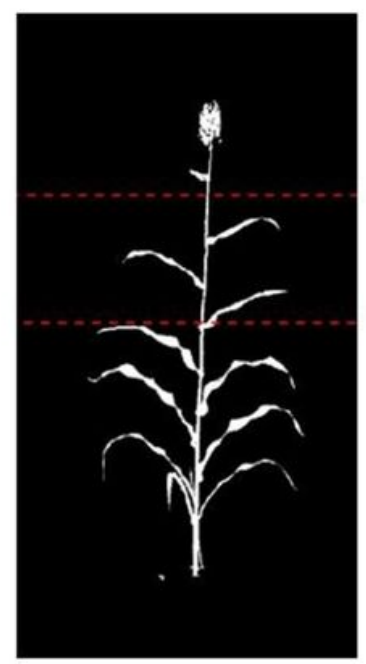

252

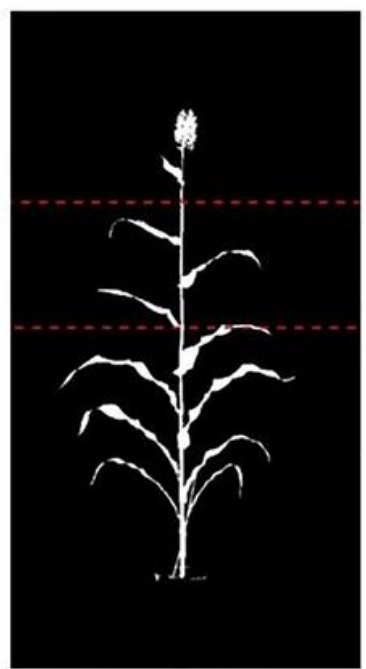

108

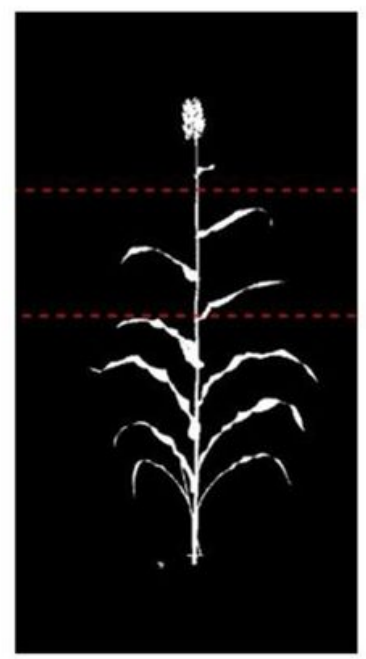

$288^{\circ}$

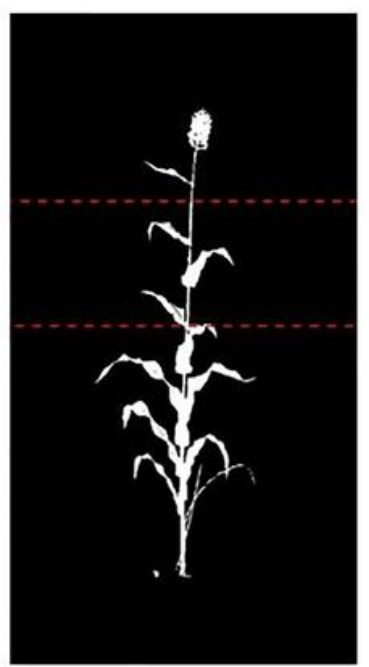

$144^{\circ}$

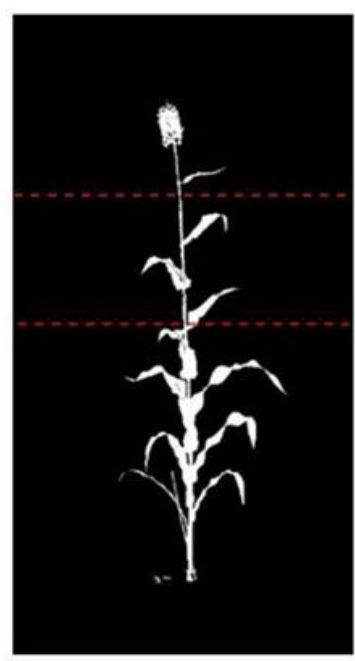

$324^{\circ}$

Figure 3

Ten different binary images converted from RGB from 0 to 360 degree. 


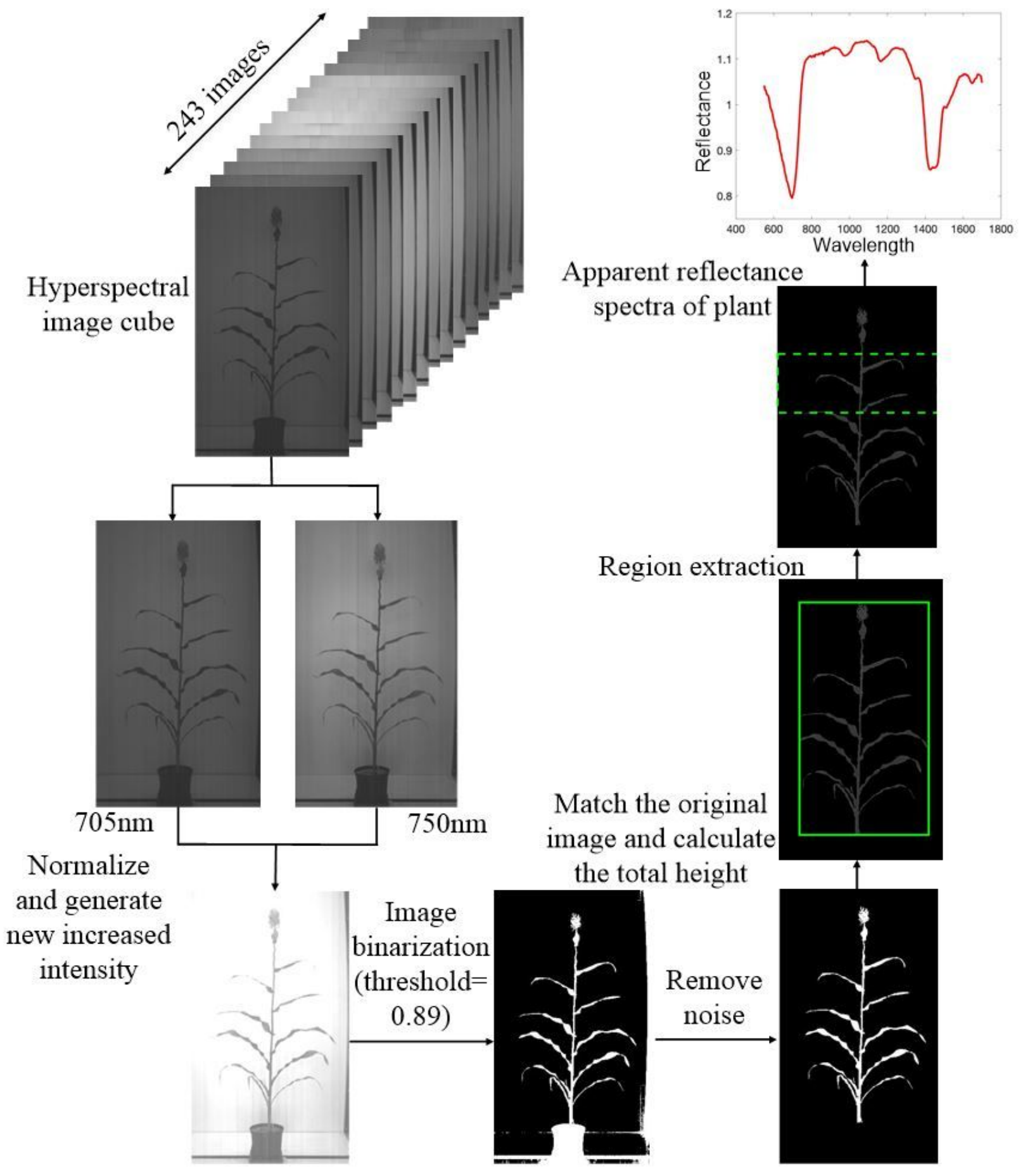

Figure 4

Flowchart showing the steps in hyperspectral image analysis to obtain apparent reflectance spectra 


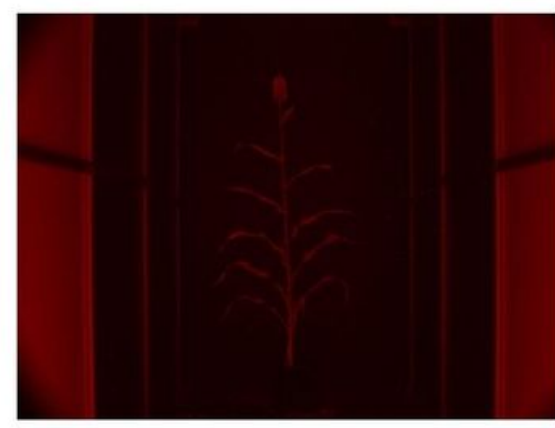

a. Initial fluorescence plant image

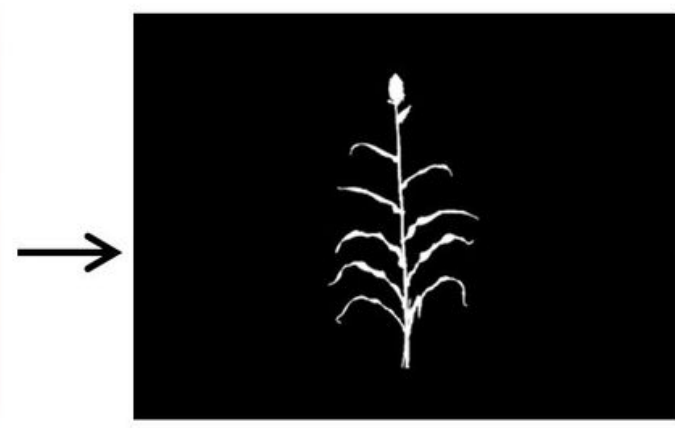

b. Thresholding with the color index to binary image

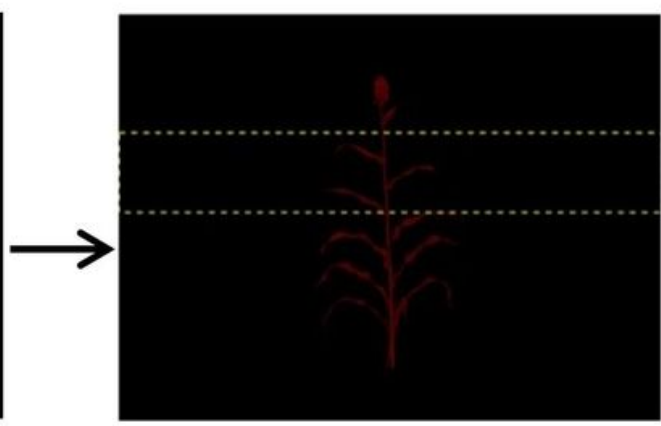

c. Extraction of the area with leaf 2,3 and 4

\section{Figure 5}

Process flow of image processing steps used in the extraction of plant's projected chlorophyll content from the fluorescence images.
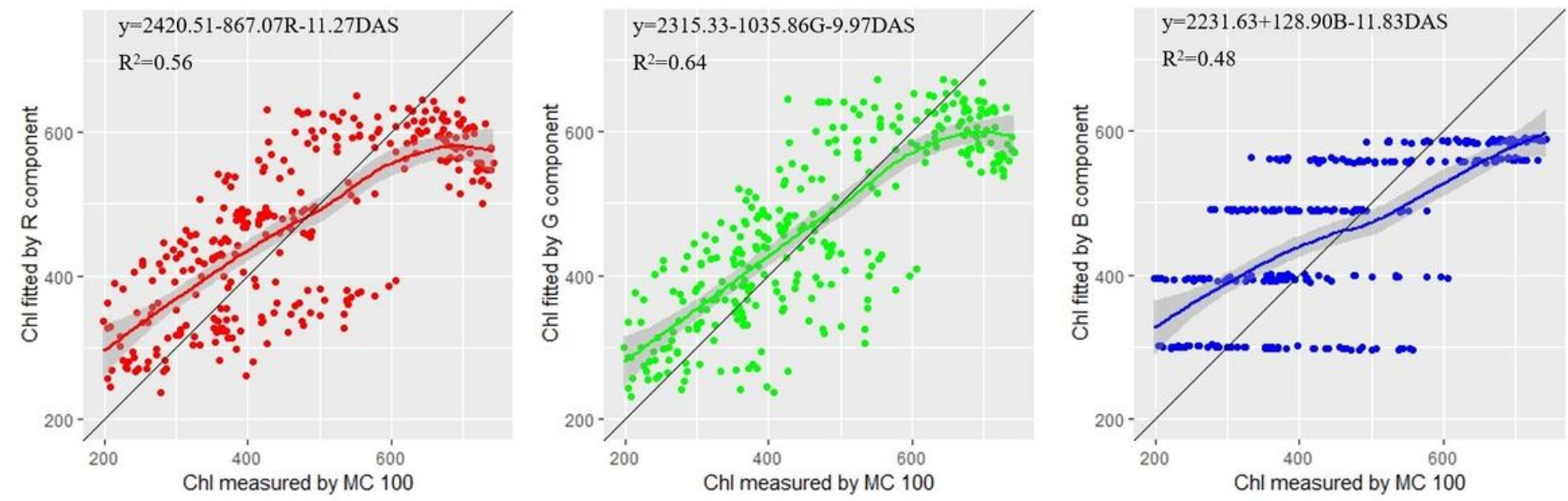

\section{Figure 6}

The correlations between the $\mathrm{Chl}$ values of measured by $\mathrm{MC} 100$ with predicted by $\mathrm{R}, \mathrm{G}$ and $\mathrm{B}$ component and DAS.
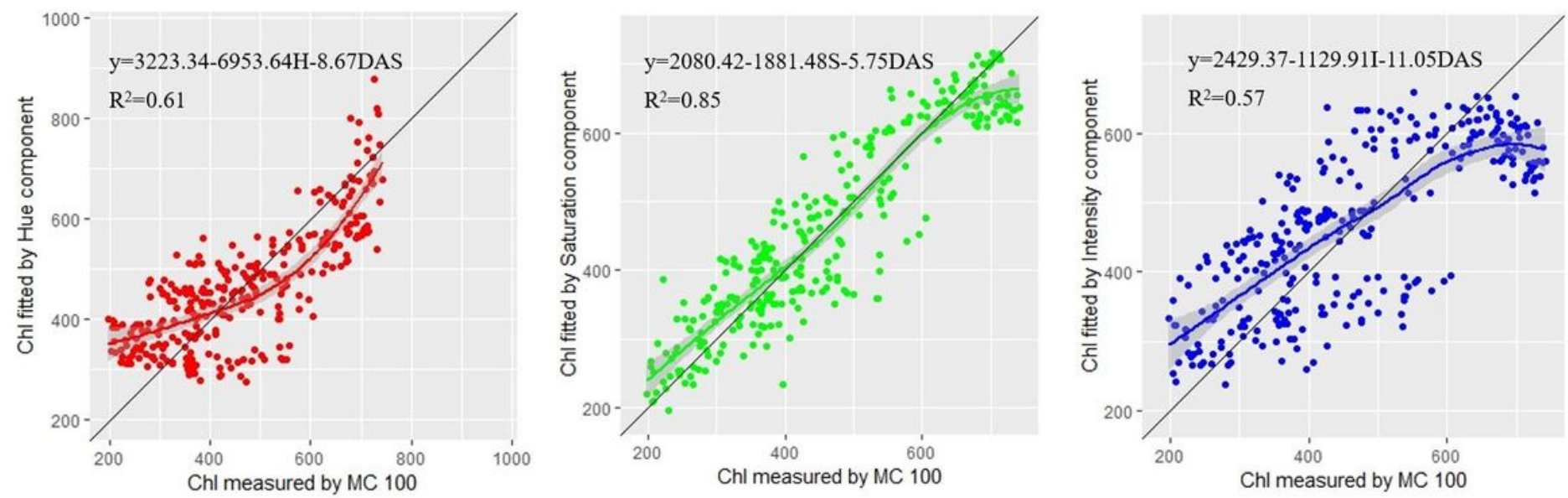


\section{Figure 7}

The correlations between the values of hue, saturation and intensity with chlorophyll content
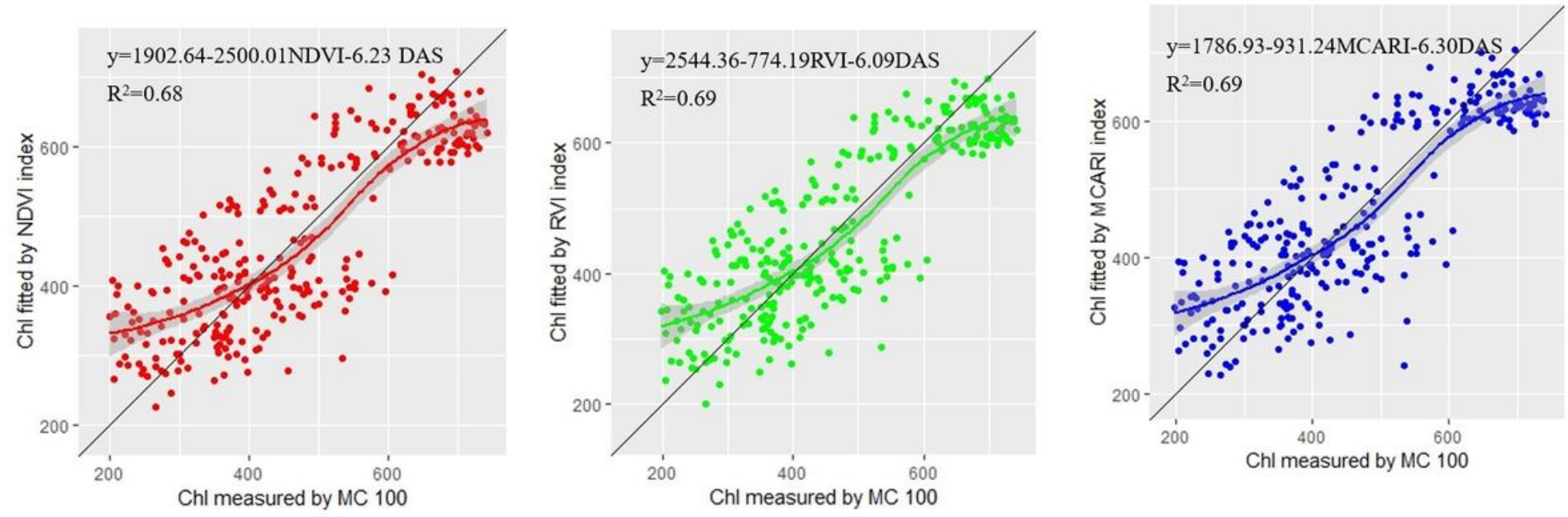

Figure 8

The correlations between the values of hyperspectral image with chlorophyll content 


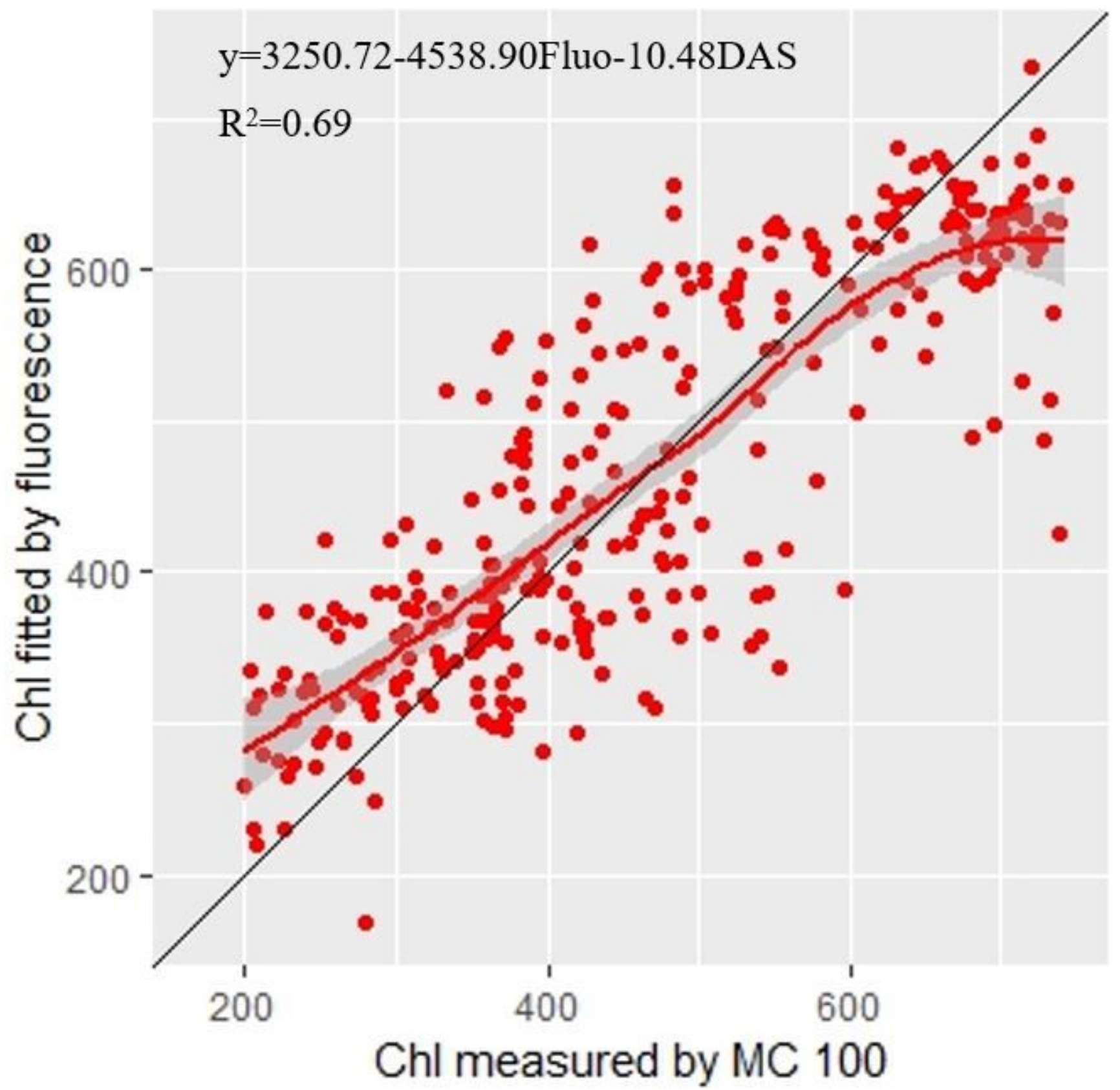

Figure 9

The correlations between the values of fluorescence image with chlorophyll content 


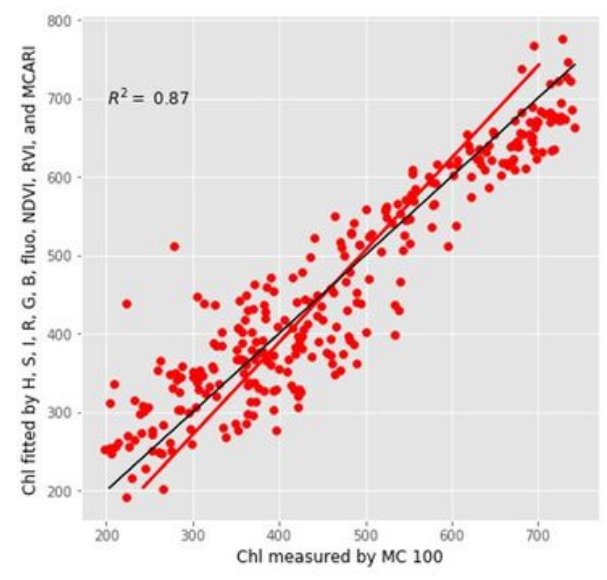

(a) Model 1 (without DAS)

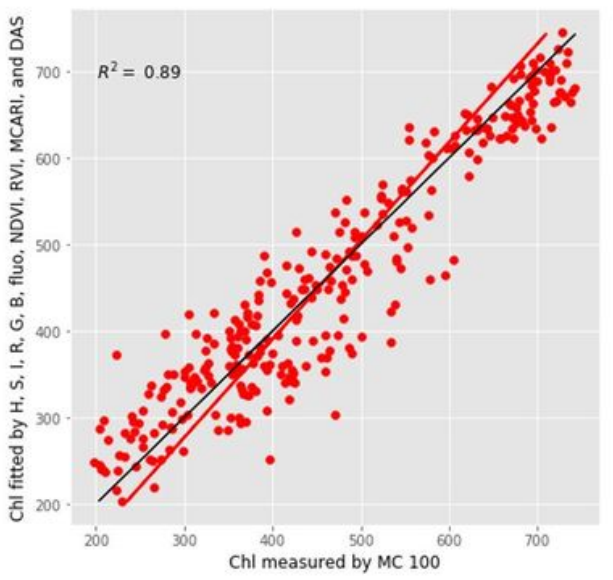

(b) Model 2 (with DAS)

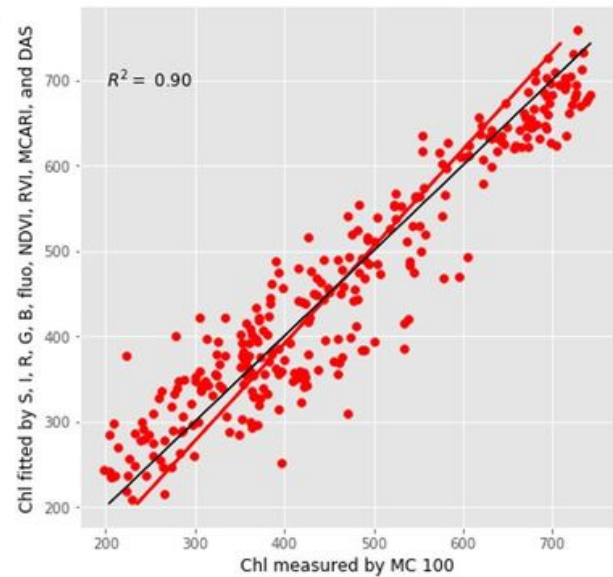

(c) Model 2 (with DAS and feature

'Hue' reduction)

\section{Figure 10}

The correlations between the selected vegetation indices computed from different imaging data with chlorophyll content

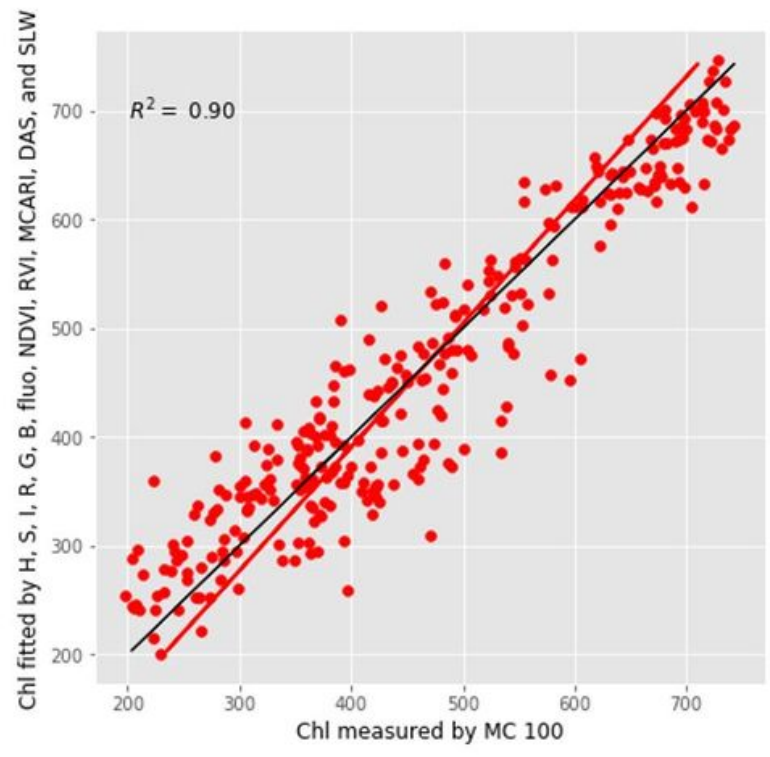

(a) Model 2 (with DAS and SLW)

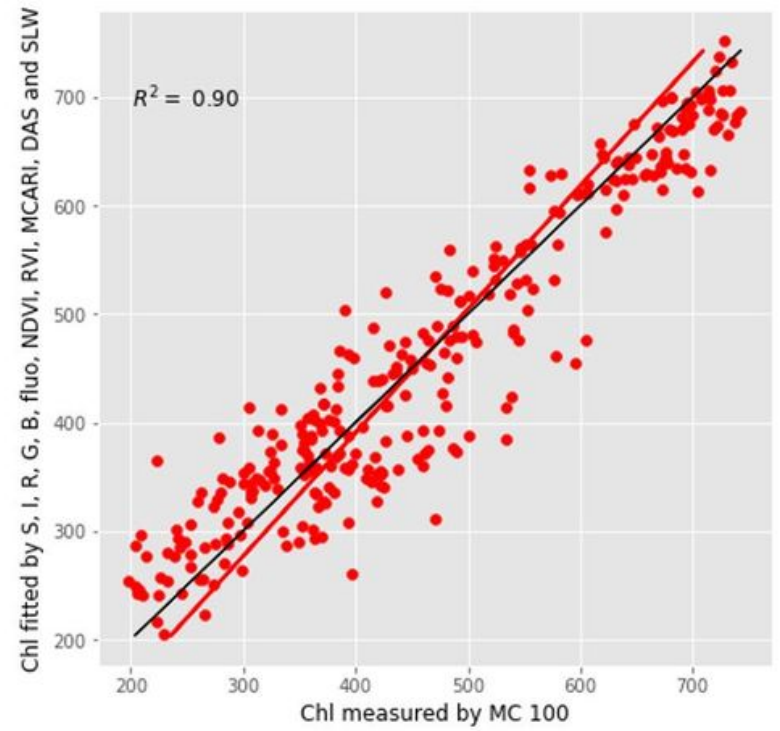

(c) Model 2 (with DAS, SLW and feature 'Hue' reduction)

\section{Figure 11}

The correlations between the selected vegetation indices computed from different imaging data and SLW with chlorophyll content 